Article

\title{
Composites Based on Poly(Lactic Acid) (PLA) and SBA-15: Effect of Mesoporous Silica on Thermal Stability and on Isothermal Crystallization from Either Glass or Molten State
}

\author{
Tamara M. Díez-Rodríguez, Enrique Blázquez-Blázquez@ Ernesto Pérez and María L. Cerrada * \\ Instituto de Ciencia y Tecnología de Polímeros (ICTP-CSIC), Juan de la Cierva 3, 28006 Madrid, Spain; \\ t.diez@ictp.csic.es (T.M.D.-R.); enrique.blazquez@ictp.csic.es (E.B.-B.); ernestop@ictp.csic.es (E.P.) \\ * Correspondence: mlcerrada@ictp.csic.es; Tel.: +34-912-587-474
}

Received: 29 October 2020; Accepted: 16 November 2020; Published: 19 November 2020

\begin{abstract}
Several composites based on an L-rich poly(lactic acid) (PLA) with different contents of mesoporous Santa Barbara Amorphous (SBA-15) silica were prepared in order to evaluate the effect of the mesoporous silica on the resultant PLA materials by examining morphological aspects, changes in PLA phases and their transitions, and, primarily, the influence on some final properties. Melt extrusion was chosen for the obtainment of the composites, followed by quenching from the melt to prepare films. Completely amorphous samples were then attained, as deduced from X-ray diffraction and differential scanning calorimetry (DSC) analyses. Thermogravimetric analysis (TGA) results demonstrated that the presence of SBA-15 particles in the PLA matrix did not exert any significant influence on the thermal decomposition of these composites. An important nucleation effect of the silica was found in PLA, especially under isothermal crystallization either from the melt or from its glassy state. As expected, isothermal crystallization from the glass was considerably faster than from the molten state, and these high differences were also responsible for a more considerable nucleating role of SBA-15 when crystallizing from the melt. It is remarkable that the PLA under analysis showed very close temperatures for cold crystallization and its subsequent melting. Moreover, the type of developed polymorphs did not accomplish the common rules previously described in the literature. Thus, all the isothermal experiments led to exclusive formation of the $\alpha$ modification, and the observation of the $\alpha^{\prime}$ crystals required the annealing for long times at temperatures below $80^{\circ} \mathrm{C}$, as ascertained by both DSC and X-ray diffraction experiments. Finally, microhardness (MH) measurements indicated a competition between the PLA physical aging and the silica reinforcement effect in the as-processed amorphous films. Physical aging in the neat PLA was much more important than in the PLA matrix that constituted the composites. Accordingly, the MH trend with SBA-15 content was strongly dependent on aging times.
\end{abstract}

Keywords: PLA and SBA-15 composites; thermal stability; isothermal crystallization; polymorphism; microhardness

\section{Introduction}

Poly(lactic acid) (PLA) possesses several attractive characteristics. Among others, it is obtained from renewable resources, and it is biodegradable, biocompatible, and semicrystalline. All of these aspects have led to its use in both specific and commodity applications [1,2].

The monomer of this aliphatic polyester, the lactic acid, presents two stereoisomers $L$ - and $D$-lactic acid and, consequently, two dimers named $L$ - and $D$-lactide. Commercial PLA grades with the most industrial relevance are those containing only around $1-10 \%$ of $D$-lactide. Regardless of the 
final application, the D-lactide content in an L-rich PLA (commonly labeled simply as PLA) is essential because it controls characteristics as important as the crystallization rate, transparency, and melting temperature. Its significance becomes even greater once one considers that the overall nucleation and crystallization rates of PLA are relatively low.

Homopolymers of L-rich PLA exhibit different crystalline structures: $\alpha^{\prime}, \alpha, \beta$, and $\gamma[3-7]$. The $\alpha^{\prime}$ and $\alpha$ crystals are developed under most processing conditions depending on thermal history. The $\beta$ polymorph is generated at elevated temperatures through the deformation of $\alpha$ crystallites [5-7]. The $\gamma$ phase shows a very different chain conformation and packing compared with those found in the $\alpha$ polymorph [4]. In addition, a mesomorphic phase can be obtained by stretching at temperatures lower than around $80^{\circ} \mathrm{C}[8,9]$.

The two former $\alpha^{\prime}$ and $\alpha$ crystal forms are, however, the most common polymorphs, showing a remarkable similarity. Even so, those subtle structural variations of the $\alpha^{\prime}$ and the $\alpha$ phases can lead to dramatic changes in properties. Furthermore, a transformation from the $\alpha^{\prime}$ to the $\alpha$ form has also been observed and characterized [10].

In spite of the aforementioned similitude, the crystalline differences between the $\alpha^{\prime}$ and the $\alpha$ lattices are related to the fact that the former is consistent with a hexagonal packing by $\mathrm{X}$-ray diffraction (i.e., the ratio of $a$-axis to $b$-axis is $\sqrt{3}$ [11]), while the $\alpha$ crystal displays an orthorhombic unit cell. Moreover, vibrational spectroscopy has shown changes in the conformation and packing of PLA chains for the two crystalline phases [10-16]. The $\alpha$ phase consists of a $10_{3}$ helix conformation, while the $\alpha^{\prime}$ chains exhibits a distorted helix one [17]. There are also important variations in their heat of fusion [18], although the structural parameters of the two crystalline phases are nearly the same. All of these features suggest that inter-chain interactions, from carbonyl and methyl functional groups, can be quite different. These interactions have been attributed to the relative orientation of the molecular dipoles in the unit cell $[15,18]$.

As discussed, PLA is characterized by relatively low overall nucleation and crystallization rates. Accordingly, numerous investigations have been focused on the enhancement of PLA crystallization kinetics [19] by adding nucleants to increase nucleation density or by incorporating plasticizers to boost chain mobility. Common nucleating agents used up to now include [16,19-27]: $\mathrm{CaCO}_{3}, \mathrm{TiO}_{2}$, talc, calcium lactate, carbon nanotubes, graphene oxide, nanoclay, and hydrazides.

Ordered mesoporous silicas can be a suitable alternative to nucleating agents since they can interact with polymeric chains, either from the exterior of the particles or the interior of the empty pores existing in their structures if macromolecules are able to be included in that nanometric space. These silicas are characterized by the presence of well-organized arrangements at long range. Mobil Composition of Matter MCM-41 and Santa Barbara Amorphous SBA-15 are the best-known members, and both are constituted by hollow channels ordered in hexagonal frames [28,29]. Their pore size is the main difference between them, the diameter ranging from 2 to $4 \mathrm{~nm}$ in the former [28] and varying from 5 to $10 \mathrm{~nm}$ in the latter [29]. These ordered porous silicas on the nanoscale have found diverse applications in several fields, including catalysis, coatings, optics, drug delivery, diagnostics, gas-separation, bio-separation, cosmetics, and nanotechnology.

Composites achieved from the incorporation of different contents of pristine SBA-15 silica into an L-rich PLA can then turn out very interesting due to the increasing importance of materials based on PLA and the extensive features of mesoporous silicas. Furthermore, these materials have been hardly evaluated [30]. Interest is even greater if the selected processing technique is melt extrusion since it is a cost-effective and an environmentally-friendly transformation approach that does not require the use of solvents. Therefore, the purpose of this research was to prepare the as-processed amorphous films for materials based on PLA and neat SBA-15 particles by extrusion, as well as to evaluate their thermal stability, crystallization capability (under dynamic or isothermal conditions), and mechanical response. For that, the resultant composites after extrusion were analyzed, with attention paid to the exhibited morphological aspects, the changes in PLA phases and their transitions, and, primarily, the influence of SBA-15 silica on the materials' final properties (thermal 
stability or mechanical behavior). Numerous techniques were required in this research, including Transmission electron microscopy (TEM), scanning electron microscopy (SEM), X-ray experiments with conventional and synchrotron radiation, Raman spectroscopy, thermogravimetric analysis (TGA), differential scanning calorimetry (DSC), and microhardness tests. These composites could find applicability by themselves, but their application fields could be even enlarged if these mesostructures were modified in a previous stage. Thus, functionalized composites based on PLA and decorated mesoporous silica could be attained with specific functionalities, such as antimicrobial, drug carrier, and $\mathrm{CO}_{2}$ capture features, thus allowing for the achievement of very versatile PLA materials.

\section{Materials and Methods}

\subsection{Materials and Chemicals}

A commercially available PLA from NatureWorks ${ }^{\circledR}$ (Minnetonka, MN, USA) was used in this study. Its grade product was labeled as 3051D, with content in $L$-isomer units of about $96 \mathrm{~mol} \%$, a melt flow index of $6.5 \mathrm{~g} / 10 \mathrm{~min}\left(190^{\circ} \mathrm{C}\right.$ and $\left.2.16 \mathrm{~kg}\right)$, and a density of $1.25 \mathrm{~g} / \mathrm{cm}^{3}$. Its weight-average molecular weight $\left(M_{w}\right)$ and molecular weight distribution $\left(M_{w} / M_{n}\right)$ were $148.6 \mathrm{~kg} / \mathrm{mol}$ and 1.94 , respectively, as determined from gel permeation chromatography (GPC) [9].

The SBA-15 particles were purchased from Sigma-Aldrich (San Luis, MO, USA) (specific surface area, $S_{\mathrm{BET}}=517 \mathrm{~m}^{2} / \mathrm{g}$; total pore volume, $V_{t}=0.83 \mathrm{~cm}^{3} / \mathrm{g}$; and average mesopore diameter, $\left.D_{p}=6.25 \mathrm{~nm}[31]\right)$ and were used as received.

\subsection{Composite and Film Preparation}

Composites with different contents of SBA-15 particles $(1,3,6$, and $9 \%$ in weight, labeled as PLA-SBA1, PLA-SBA3, PLA-SBA6, and PLA-SBA9, respectively) were processed by melt extrusion in a corotating twin-screw micro extruder (Rondol, Rondol Industrie, Nancy, France) at a rate of $60 \mathrm{rpm}$. Prior to extrusion, both the polymer and SBA- 15 were dried. The former was placed in an oven at $100^{\circ} \mathrm{C}$ for $20 \mathrm{~min}$ followed by drying under vacuum at $85^{\circ} \mathrm{C}$ for $2 \mathrm{~h}$. The SBA- 15 particles were dried under vacuum at $100{ }^{\circ} \mathrm{C}$ for $24 \mathrm{~h}$. In the extruder, screw temperature profiles of $125,160,190,190$ and $185^{\circ} \mathrm{C}$ were used from the hopper to the die, with the length-to-diameter ratio being 20:1. Then, films were obtained by compression molding in a hot-plate Collin press (Collin $\mathrm{GmbH}$, Maitenbeth, Germany). The first stage was the maintenance of the material at a temperature of $185{ }^{\circ} \mathrm{C}$ and at a pressure of 30 bar for $6 \mathrm{~min}$. After that, a cooling process was applied to the different composites from their molten state to room temperature for $4 \mathrm{~min}$ at the relatively fast rate of around $80^{\circ} \mathrm{C} / \mathrm{min}$ and at a pressure of 30 bar.

\subsection{Transmission Electron Microscopy}

Morphological details of the mesoporous SBA-15 silica were obtained by TEM. Measurements were performed at room temperature with a $200 \mathrm{kV}$ JEM-2100 JEOL microscope (JEOL Ltd., Tokyo, Japan). The particles were dispersed in acetone in an ultrasonic bath for $5 \mathrm{~min}$ and then deposited into a holder prior to observation.

\subsection{Scanning Electron Microscopy}

SBA-15 particle dispersion within the PLA matrix was evaluated by high resolution field emission scanning electron microscopy (FESEM). Experiments were carried out with a Hitachi S-8000 (Hitachi Co., Tokyo, Japan) at room temperature in different cryo-fractured sections of composites with distinct mesoporous contents. Those thin sections of around $40 \mathrm{~nm}$ were cut by cryo-ultramicrotomy (Leica EM UC6, Leica Microsystems GmbH, Wetzlar, Germany) at $-120^{\circ} \mathrm{C}$ and deposited in a holder. 


\subsection{X-ray Experiments with Conventional and Synchrotron Radiation}

Wide angle X-ray diffraction (WAXD) patterns at room temperature were recorded to examine the crystalline structure of the polymeric matrix in the reflection mode by using a Bruker D8 Advance diffractometer provided with a position-sensitive detector (PSD) Vantec detector (from Bruker, Madison, WI, USA). $\mathrm{Cu} \mathrm{K} \alpha$ radiation $(\lambda=0.15418 \mathrm{~nm})$ was used, operating at $40 \mathrm{kV}$ and $40 \mathrm{~mA}$. The parallel beam optics were adjusted by a parabolic Göbel mirror with a horizontal grazing incidence Soller slit of $0.12^{\circ}$ and an LiF monochromator. The equipment was calibrated with different standards. A step scanning mode was employed for the detector. The diffraction scans were collected with a $2 \theta$ step of $0.024^{\circ}$ and 0.2 s per step.

Real-time variable-temperature simultaneous small-angle X-ray scattering (SAXS) and WAXD experiments were carried out with synchrotron radiation in Non Crystalline Diffraction beamline (BL11-NCD) at ALBA (Cerdanyola del Valles, Barcelona, Spain) at a fixed wavelength of $0.1 \mathrm{~nm}$. A Pilatus 1M detector (Dectris Ltd., Baden-Daettwil, Switzerland) was used for SAXS (off beam, at a distance of $296 \mathrm{~cm}$ from sample) and a Rayonix one (Rayonix, Evanston, IL, USA) for WAXD (at about $14.6 \mathrm{~cm}$ from the sample and a tilt angle of around 29 degrees). A Linkam unit, connected to a cooling system of liquid nitrogen, was employed for the temperature control. The calibration of spacings was obtained by means of silver behenate and $\mathrm{Cr}_{2} \mathrm{O}_{3}$ standards. The initial 2D X-ray images were converted into 1D diffractograms as a function of the inverse scattering vector, $s=1 / d=2 \sin \theta / \lambda$, by means of the fast azimuthal integration python (pyFAI) code (European Synchrotron Radiation Facility, ESRF), modified by the ALBA beamline staff. Film samples of around $5 \times 5 \times 0.1 \mathrm{~mm}$ were used in the synchrotron analysis.

\subsection{Raman Spectroscopy}

Knowledge one the conformations and packing of PLA macrochains was gained via Raman spectroscopy. These experiments were performed in the Raman Micro-Spectroscopy Laboratory of the Characterization Service at ICTP-CSIC by using a Renishaw InVia Reflex Raman system (Renishaw plc, Wotton-under-Edge, UK), provided with a grating spectrometer coupled to a confocal microscope, as well as a Peltier-cooled charge-coupled device (CCD) detector. A diode laser (wavelength of $785 \mathrm{~nm}$ ) was used for exciting the Raman scattering. The laser beam, with a power of $160 \mathrm{~mW}$, was focused at the sample with the aid of a $0.85 \times 100$ microscope objective. An exposure time of $1 \mathrm{~s}$ and 200 accumulations were employed in these Raman measurements. After a baseline correction, the Raman spectra were normalized to the intensity of $\mathrm{C}=\mathrm{O}$ stretching vibration of ester groups at $1772 \mathrm{~cm}^{-1}$ [32].

\subsection{Thermogravimetric Analysis}

TGA was performed with the Q500 equipment (TA Instruments, New Castle, DE, USA) of TA Instruments under nitrogen or air atmospheres at a heating rate of $10^{\circ} \mathrm{C} / \mathrm{min}$. The degradation temperatures of the distinct materials were determined, together with the exact SBA-15 amounts incorporated into the composites prepared by extrusion. These amounts were estimated as an average of values obtained from the two environments.

\subsection{Differential Scanning Calorimetry}

Calorimetric analyses were carried out in a TA Instruments Q100 calorimeter (TA Instruments, New Castle (DE) USA) connected to a cooling system and calibrated with different standards. The sample weights were around $3 \mathrm{mg}$. A temperature interval from -30 to $180^{\circ} \mathrm{C}$ was studied at a heating rate of $10^{\circ} \mathrm{C} / \mathrm{min}$. For the determination of the crystallinity, a value of $93.1 \mathrm{~J} / \mathrm{g}$ was used as the enthalpy of fusion of a perfectly crystalline material $[16,33]$. 


\subsection{Microhardness}

A Vickers indenter attached to a Leitz microhardness tester (Leitz $\mathrm{GmbH}$, Oberkochen, Germany) was used to perform micro-indentation measurements undertaken at $23^{\circ} \mathrm{C}$. A contact load of $0.98 \mathrm{~N}$ and a time of $25 \mathrm{~s}$ were employed. The microhardness $(\mathrm{MH})$ value (in $\mathrm{MPa}$ ) was calculated according to the following relationship [34,35]:

$$
\mathrm{MH}=2 \sin 68^{\circ}\left(\frac{P}{d^{2}}\right)
$$

where $P$ (in $\mathrm{N}$ ) is the contact load and $d$ (in $\mathrm{mm}$ ) is the diagonal length of the projected indentation area. Diagonals were measured in the reflected light mode within $30 \mathrm{~s}$ of load removal using a digital eyepiece equipped with a Leitz computer-counter-printer (RZA-DO). This analysis provided preliminary information about dependence on aging time of mechanical features in the amorphous as-obtained materials.

\section{Results and Discussion}

\subsection{Morphological and Structural Characteristics}

Figure 1a shows TEM micrographs for the mesoporous SBA-15 silica used in this investigation. The left upper picture displays the distinctive vermicular elongated shape of these particles with an average width of $350 \mathrm{~nm}$ and length of $0.9 \mu \mathrm{m}$. The magnification shown in the right upper inset depicts the interior particle morphology consisting of the well-defined, uniform, and ordered channel structure (see within red squares) with hexagonal arrangements (see within the blue ellipse).

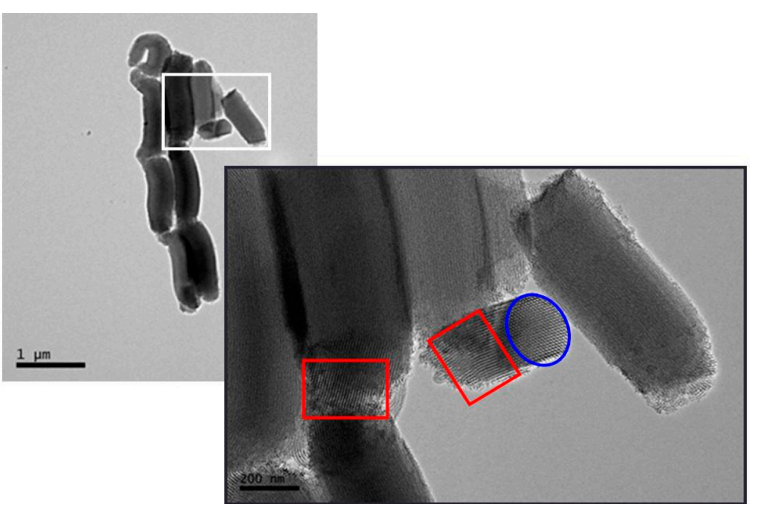

(a) SBA-15

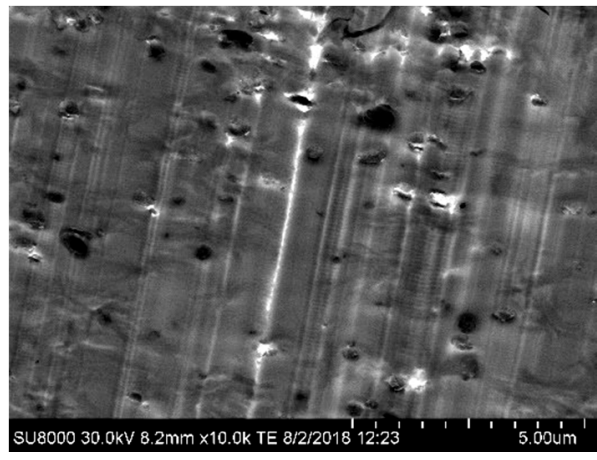

(c) PLA-SBA6

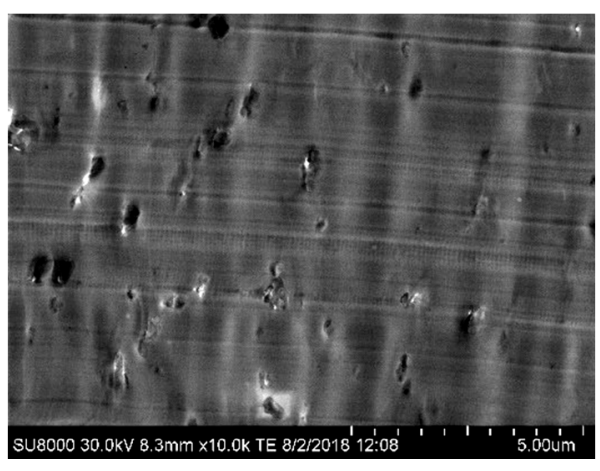

(b) PLA-SBA3

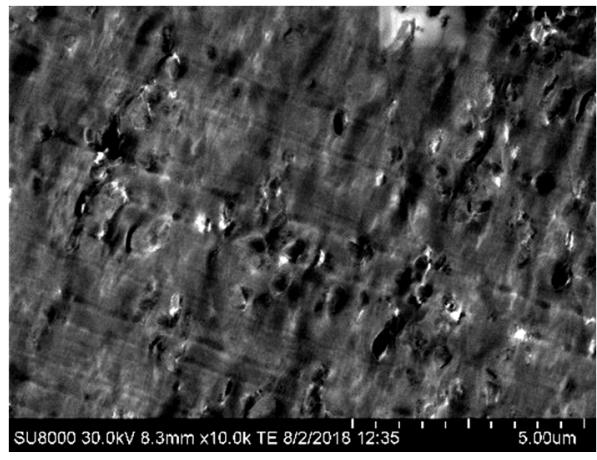

(d) PLA-SBA9

Figure 1. (a) TEM images of SBA-15 particles at a scale bar of $1 \mu \mathrm{m}$ (left) and its magnification at $200 \mathrm{~nm}$ (right). FESEM micrographs for different composites: PLA-SBA3 (b), PLA-SBA6 (c), and PLA-SBA9 (d) at a scale bar of $5 \mu \mathrm{m}$. 
The micrographs depicted in Figure 1b-d correspond to the FESEM pictures for the PLA-SBA3, PLA-SBA6, and PLA-SBA9 composites. The suitable dispersion of SBA-15 particles within the PLA matrix and the non-existence of detectable bulky inorganic domains across the films at the different mesoporous silica contents are noticeable. Some agglomerates are, nevertheless, observed as SBA-15 composition was increased, but their sizes were not excessively large and they were found in a negligible proportion. These results seem to indicate a good contact at interfaces between silica particles and the PLA polymeric matrix despite their different chemical natures: hydrophobic for PLA and hydrophilic for the mesoporous silica.

The ordered and well-defined channel structure with hexagonal arrangement presented by the mesoporous silica particles embedded in the PLA matrix was also deduced from the WAXD measurements at middle angles, as noticed in Figure 2a, for the different composites. The highly ordered hexagonal SBA-15 structure was characterized by three main diffraction peaks indexed as (100), (110), and (200) reflections, which are associated with its $p 6 \mathrm{~mm}$ hexagonal symmetry [29]. It should be commented that the lower limit of the WAXD profiles represented in Figure 2a is $1^{\circ}$ in the $2 \theta$ scale, so that the (100) reflections cannot be seen, and only the (110) and (200) main diffractions are the ones observed at this angular range. Furthermore, intensity of the specific SBA-15 reflections is significantly lowered in the composites, as much as the silica content incorporated decreases. Their position was not considerably changed although they appear to have been slightly altered. It has been described for hybrids based on polyethylene prepared by in situ polymerization [36-39] and on polypropylene ones, either obtained by in situ polymerization [40] or melt extrusion [41-43], that polymeric chains could grow up inside the hollow nanometric spaces that exist in both MCM-41 and SBA-15 particles during polymerization or could be pushed in those empty channels during the extrusion process. Accordingly, regularity at the mesoscale was not noticeably affected by the polymerization or shear forces applied during extrusion, and the hexagonal arrangement of the mesoporous silica channels was maintained.
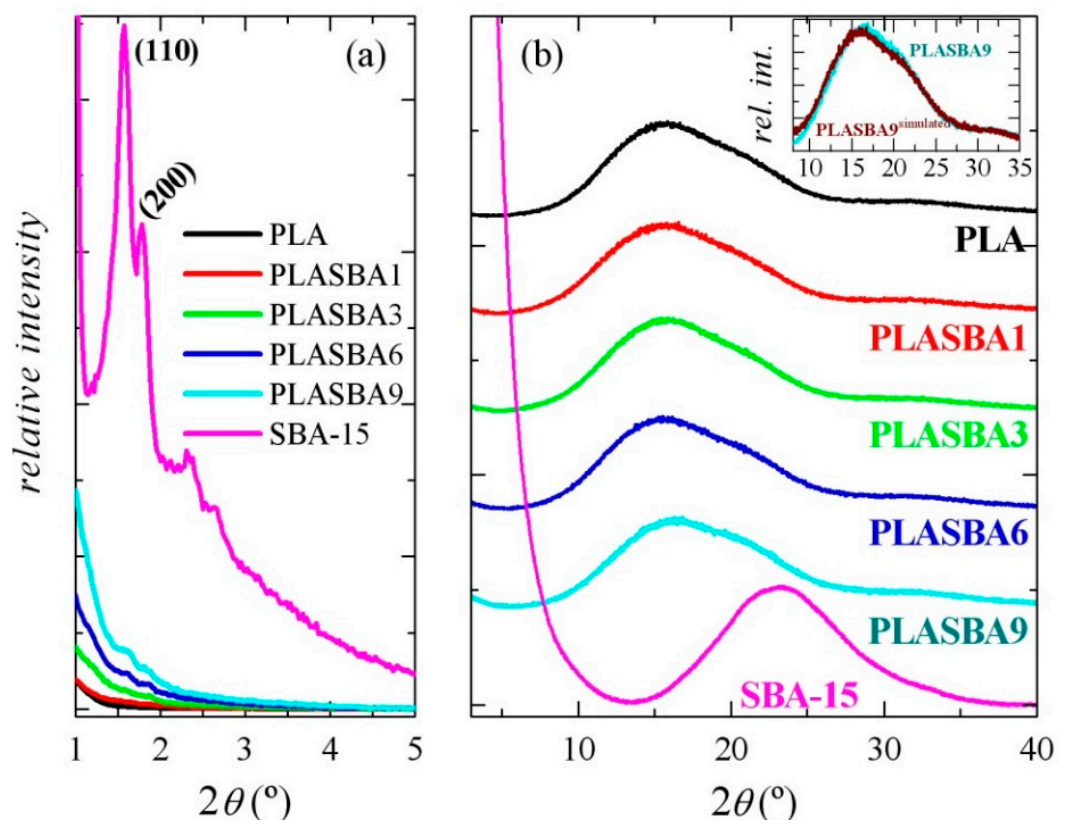

Figure 2. X-ray diffraction patterns at room temperature for pristine PLA, mesoporous SBA-15 particles, and the different composites based on PLA and distinct SBA-15 contents at middle (a) and wide angles (b). Inset: comparison between the experimental and simulated patterns (see text) for PLA-SBA9.

Figure $2 \mathrm{~b}$ shows that the processed PLA films quenched in the press were completely amorphous independently of the absence or incorporation of mesoporous SBA-15. This treatment was chosen for the films' preparation to simulate the high cooling rates generally applied during common injection molding at the industrial scale. These composites of PLA with mesoporous silica have been rather 
unexplored [30] despite their great potential, and scarce knowledge has been actually established up to now.

The lower WAXD profile corresponded to the pristine SBA-15 silica, which also displayed its amorphous nature at short range. Thus, it was characterized by a broad diffraction centered at around $2 \theta=23^{\circ}$. Accordingly, a shoulder overlapped to the main PLA amorphous halo became visible in the composites (Figure $2 \mathrm{~b}$ ) as the content in mesoporous particles increased.

The location of the PLA amorphous halo remained almost unchanged at $15.9^{\circ}$ in the composites except for the PLA-SBA9, where it was shifted to $16.5^{\circ}$, i.e., to slightly higher $2 \theta$ values, as noticed in the inset of Figure $2 b$ where the experimental pattern is compared with that simulated from the pristine constituents at their specific contents. This feature seems to indicate the establishment of some PLA-mesoporous silica interactions that led to a denser packing of the amorphous PLA chains and a slight modification of its intra and inter-chain distances in this composite. To get further information, Raman spectroscopy measurements were carried out.

Figure 3 shows the Raman shift for the different analyzed PLA materials at different vibrational zones.
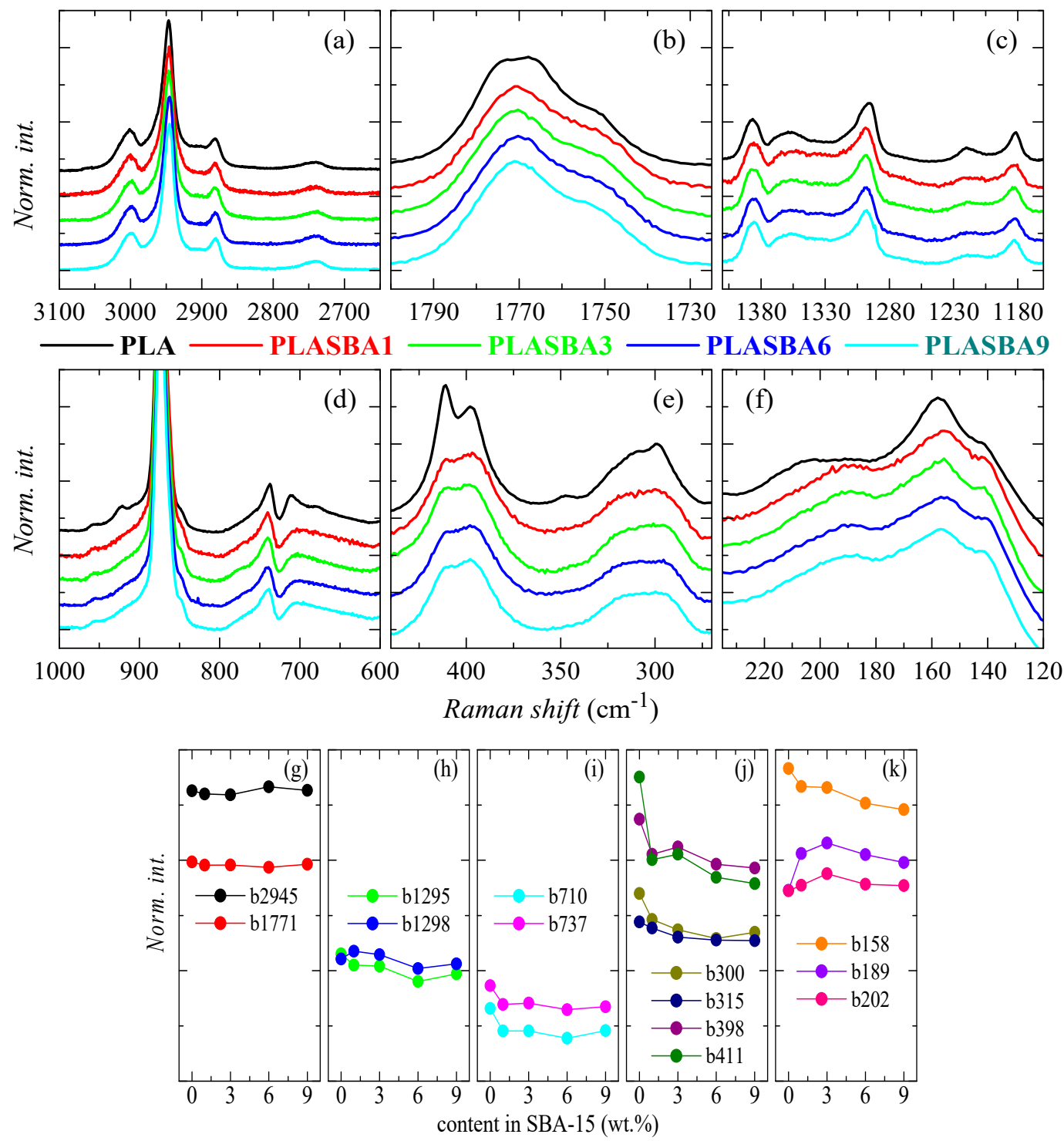

Figure 3. (a-f): Raman spectra for pristine PLA and its composites with mesoporous SBA-15 at different spectral regions; $(\mathbf{g}-\mathbf{k})$ : variation with the SBA-15 content of the normalized intensity of the indicated bands. 
Infrared and Raman spectroscopies have proven to be important tools for PLA characterization [12, 16,44-46] to distinguish between different conformations and packing, together with distinct crystalline lattices and degrees of crystallinity. In an amorphous chain, the $\operatorname{tg}^{\prime} t$ is the predominant conformational sequence for the three dihedral angles in a repeat unit of PLA $[47,48]$.

Experimental investigations also clearly displayed that structural differences between the $\alpha$ and $\alpha^{\prime}$ phases were small but significant. The $\alpha$ phase consisted of $10_{3}$ helix conformations within an orthorhombic unit cell, as noted in the Introduction. In contrast, the $\alpha^{\prime}$ chain was a distorted helix and hexagonally packed. The main changes were, then, observed in vibrations involving carbonyl or methyl groups, which could be attributed to specific interactions concerning those functional groups. As depicted in Figure 2, all of the PLA samples under study were in an amorphous state. Consequently, no important variations were expected at first approximation.

The $\mathrm{CH}$ stretching region of the Raman spectra, $2800-3100 \mathrm{~cm}^{-1}$, is represented in Figure 3a. This zone remains rather inalterable by the incorporation of SBA- 15 particles. Some differences have been found in the literature for specimens where the $\alpha$ phase was developed [18]. The carbonyl stretching region, $1700-1800 \mathrm{~cm}^{-1}$, has been described in PLA as precise for the assignment of the developed crystal polymorph $[44,46]$. Despite all the samples being amorphous, as seen in Figure $2 b$, a clear difference was observed between the neat PLA and the samples containing mesoporous SBA-15. This showed a broad band that consisted of three components, while the carbonyl band in the composites was formed by two noticeable contributions. This feature seems to indicate that the incorporation of silica changed the specific interactions between PLA chains. This might be associated with the establishment of some type of PLA-silica physical arrangement.

Figure $3 \mathrm{c}$ represents the spectral window from 1410 to $1260 \mathrm{~cm}^{-1}$. The band located at $1295 \mathrm{~cm}^{-1}$ for neat PLA was moved to $1298 \mathrm{~cm}^{-1}$ in the different composites. This change points out a denser packing in the chains of pristine PLA compared with that exhibited by the composites where SBA-15 particles were incorporated. A small reduction of its intensity was also observed in the composites at high silica contents. Similar features to these commented ones have been reported by comparison of Raman spectra for amorphous and semicrystalline PLA [49].

Particular sensitivity was also exhibited by shape and intensity of the 737 and $710 \mathrm{~cm}^{-1}$ bands, assignable to skeletal bending modes [18] (see Figure 3d). The relative intensity of the low frequency peak $\left(710 \mathrm{~cm}^{-1}\right)$ to the higher component was the greatest in the pristine PLA compared with the one shown by the composites. In addition, the band width of this low frequency component also decreased for the neat PLA. These characteristics seemed to again indicate that the amorphous chains in the pristine PLA were arranged in more compact conformations than PLA chains existing in composites with SBA-15 particles.

Another spectral region of particular interest was that where the deformation vibrations of the $\mathrm{CCO}$ and COC groups were coupled with $\mathrm{CCH}_{3}$ groups, typically seen at 420 and $290 \mathrm{~cm}^{-1}$ (see Figure 3e). The presence of the mesoporous silica significantly affected the shape of the vibrational bands appearing in this spectral window. An evident splitting was noticed at 411 and $398 \mathrm{~cm}^{-1}$, which involved the $\mathrm{C}=\mathrm{O}$ in plane bending. This split has previously been observed in the spectrum of crystallized samples, and it has not been seen in that for amorphous samples [44]. This feature seems to demonstrate that the neat PLA exhibited conformations that boost a packing similar to that existing in $\alpha$ crystals. Additional variations were also shown at about $315 \mathrm{~cm}^{-1}$, indicating the existence of specific interactions between the carbonyl and methyl groups. This behavior was analogous to such exhibited between samples containing $\alpha$ or the $\alpha^{\prime}$ crystals [18]. Nevertheless, the PLA macrochains in all the analyzed samples were amorphous, as displayed Figure $2 b$.

Finally, a reduction in intensity and a displacement to lower frequencies were observed in the bands at about 200 and $150 \mathrm{~cm}^{-1}$, as deduced from Figure 3f. These facts were consistent with a less compact packing between the PLA chains in the composites because of the presence of the SBA-15 particles. 
The previous aspects can also be clearly noticed in Figure $3 \mathrm{~g}-\mathrm{k}$. Thus, the practical constancy of the band at $2945 \mathrm{~cm}^{-1}$ is observed in Figure $3 \mathrm{~g}$, as can that of the one at $1771 \mathrm{~cm}^{-1}$, whose area was considered for the normalization of the spectra. The shifting of the band located at $1295 \mathrm{~cm}^{-1}$ for neat PLA to $1298 \mathrm{~cm}^{-1}$ in the different composites can be deduced in Figure $3 \mathrm{~h}$ from their initial decrease or increase, respectively. Figure $3 i$ indicates the great sensitivity of the bands at 710 and $737 \mathrm{~cm}^{-1}$, the first being the one displaying the highest relative change. Figure $3 j$ shows the variations of the bands at $411,398,315$, and $300 \mathrm{~cm}^{-1}$, with an especially high decrease between PLA and the composites of the band at $411 \mathrm{~cm}^{-1}$. Finally, Figure 3k depicts the behavior of the bands at 202, 189, and $158 \mathrm{~cm}^{-1}$, characterized by an initial intensity increase for the first two bands and a very important decrease of the band at $158 \mathrm{~cm}^{-1}$ from neat PLA to the different composites.

In summary, the presence of SBA-15 particles seems to alter the packing within the PLA chains, probably due to the establishment of some kind of interactions between PLA and SBA-15 in the composites. The effects of these changes on the final properties and phase transitions of the PLA chains are examined shortly.

\subsection{Thermal Stability}

PLA undergoes hydrolytic degradation and mesoporous SBA-15 particles are easily hydrophilic. This PLA degradation is primarily important at high temperatures and leads to a reduction of its molecular weight and a loss of its overall properties. The influence of SBA-15 silica on PLA's thermal stability is thus important to be examined because composites are prepared by extrusion at high temperature. Accordingly, this is analyzed next.

Mesoporous silicas have also been used, sometimes, as catalysts for decomposition. This effect was found by Marcilla et al. [50] when they used TGA to study the degradation of PE under $\mathrm{N}_{2}$ in the presence and absence of mesoporous MCM-41. Aguado et al. [51] showed the efficiency of mesoporous aluminosilicate MCM-41 as promoter for the degradation of polyolefins into liquid fuels. This role as a promoter of decomposition was also found when MCM-41 silica was used as a catalyst carrier and filler for in situ polymerized polyethylene-based composites employing either neat mesoporous particles or those decorated with undecenoic acid or silanes $[37,52,53]$.

Figure 4 shows the TGA curves and their derivatives (DTGA) under inert and oxidative conditions for these extruded materials. As observed, inert decomposition occurred in a single step from 300 to $400{ }^{\circ} \mathrm{C}$. The presence of mesoporous silica did not greatly affect either how the process took place or its location. A shift to slightly higher temperature was, however, observed, as detailed in Table 1. Moreover, a narrowing of the degradation process in the composites can be deduced from the DTGA curves.

Table 1. TGA results under nitrogen and air atmospheres for neat PLA and composites prepared by melt extrusion: temperature of a loss weight of $10 \%\left(\mathrm{~T}_{10 \%}\right)$ and temperature at the maximum $\left(\mathrm{T}_{\max }\right)$, together with the SBA-15 wt.\% content in both environments and its average.

\begin{tabular}{|c|c|c|c|c|c|c|c|}
\hline \multirow[b]{2}{*}{ Sample } & \multirow{2}{*}{$\begin{array}{c}\text { Average } \\
\text { SBA-15 wt. } \% \\
\text { Content }\end{array}$} & \multicolumn{3}{|c|}{ Inert Atmosphere } & \multicolumn{3}{|c|}{ Oxidative Atmosphere } \\
\hline & & $\mathrm{T}_{10 \%}\left({ }^{\circ} \mathrm{C}\right)$ & $\mathrm{T}_{\max }\left({ }^{\circ} \mathrm{C}\right)$ & $\begin{array}{c}\text { SBA-15 } \\
\text { wt. \% Content }\end{array}$ & $\mathrm{T}_{10 \%}\left({ }^{\circ} \mathrm{C}\right)$ & $\mathrm{T}_{\max }\left({ }^{\circ} \mathrm{C}\right)$ & $\begin{array}{c}\text { SBA-15 } \\
\text { wt.\% Content }\end{array}$ \\
\hline PLA & 0 & 328.0 & 361.2 & 0 & 333.0 & 364.6 & 0 \\
\hline PLA-SBA1 & 1.4 & 339.5 & 368.0 & 1.6 & 324.0 & 360.6 & 1.3 \\
\hline PLA-SBA3 & 2.6 & 331.0 & 359.0 & 2.8 & 325.0 & 355.4 & 2.4 \\
\hline PLA-SBA6 & 5.8 & 341.0 & 365.6 & 6.1 & 328.5 & 356.2 & 5.6 \\
\hline PLA-SBA9 & 9.3 & 343.0 & 369.4 & 9.6 & 336.5 & 362.4 & 8.9 \\
\hline
\end{tabular}



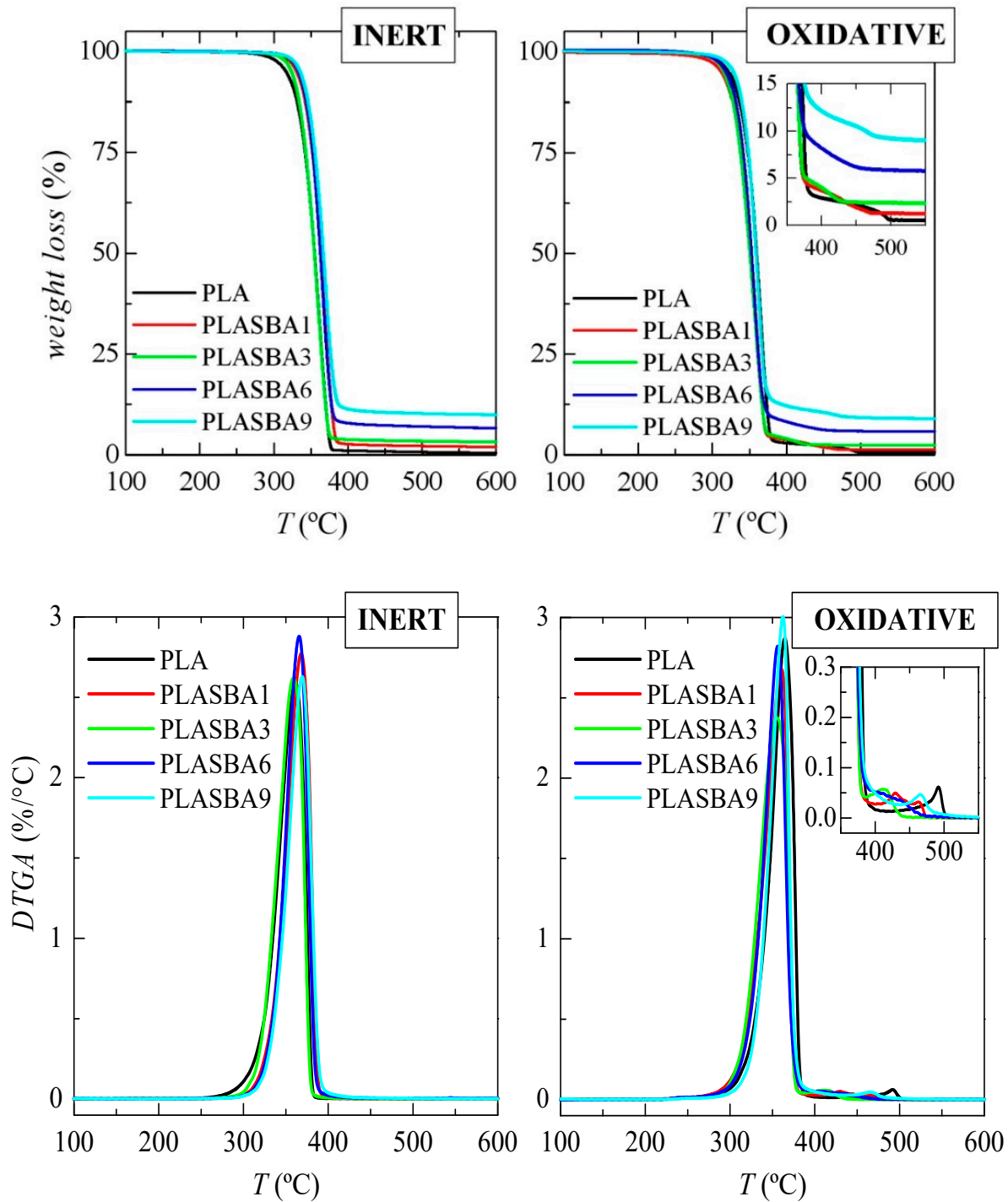

Figure 4. TGA curves under inert (left) and oxidative (right) atmospheres for the neat PLA and its composites with SBA-15 at different contents prepared by melt extrusion (top representations), as well as their corresponding derivative TGA (DTGA) curves (bottom representations).

TGA curves under air exhibit two degradation processes. The main one took place at lower temperatures and involved the most of the weight loss, around $97 \%$, and the secondary mechanism occurred just after the primary process ended. The incorporation of mesoporous silica did not have a significant role in the principal PLA decomposition stage, similarly to what was observed in the degradation performed under inert condition. Nevertheless, it seemed that presence of SBA-15 particles led to a little displacement to lower values of the temperature of maximum degradation and shortened the temperature interval at which the minor process occurred, as deduced from the DTGA curves under oxidative conditions.

All of these results demonstrated that presence of SBA-15 particles in a PLA matrix does not exert any significant catalytic effect in these composites. In fact, they become a little more stable if an inert atmosphere is used. It is interesting that a comparison of the TGA curves obtained under both environments shows that PLA degraded at an analogous range of temperature.

Furthermore, the exact amount of incorporated mesoporous silica was also estimated from these thermogravimetric curves achieved under the two environments. These data are also reported in Table 1 -an average value was assessed. The fact that the two determinations were rather similar was 
an indirect effect of the homogeneity in the distribution of the content of the SBA-15 particles within the material at a given composition.

\subsection{Existing Phases and Their Transitions}

Figure 5 shows the phase transitions observed in the neat PLA and its composites with SBA-15 during a first heating, cooling, and second heating runs performed at $10^{\circ} \mathrm{C} / \mathrm{min}$. Knowledge of phase transition is mandatory to understand properties in polymers, but it is even more important in PLA because its glass transition undergoes physical aging and its crystallization takes place slowly, both facts exerting a key role in its dimensional stability. Analysis is now focused on the crystallization process since the main purpose of adding SBA- 15 particles was to learn their influence on the ordering arrangement of PLA chains.

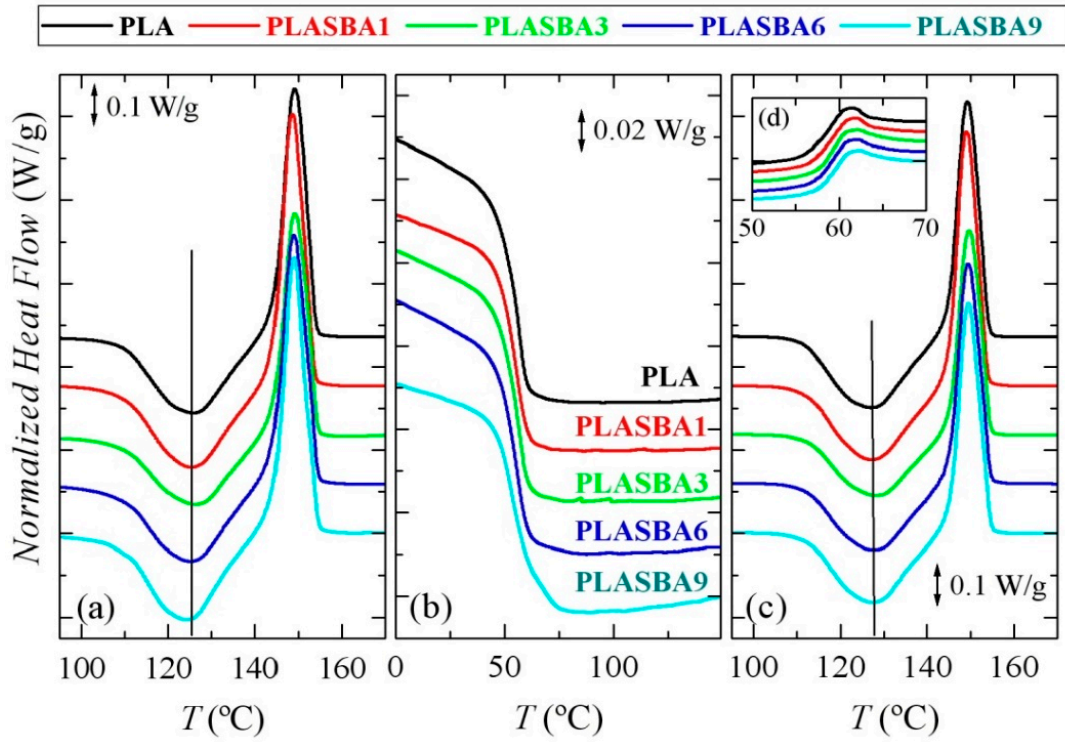

Figure 5. DSC curves performed at $10^{\circ} \mathrm{C} / \mathrm{min}$ for PLA and its composites with SBA-15, normalized to the actual PLA amount: (a) first heating, (b) cooling from the melt, (c) second heating, and (d) interval for glass transition during second heating.

Figure $5 \mathrm{a}$ is related to the first heating experiments. Glass transition (not shown) appeared in all the samples at approximately $57^{\circ} \mathrm{C}$, i.e., the incorporation of mesoporous silica seemed not to greatly affect its location. At higher temperatures, the cold crystallization process of PLA was seen. It took place at $126.5^{\circ} \mathrm{C}$ in all the samples with the exception of PLA-SBA9 where a shift to $124.5^{\circ} \mathrm{C}$ occurred. At this highest content in mesoporous silica, a slight nucleating effect was thus observed when crystallization occurred from the glassy state. The intensity of cold crystallization remained rather constant independently of the SBA-15 content. Once this exothermic event finished, a melting process was initiated. It was characterized by the appearance of a unique peak whose maximum was seen at $149^{\circ} \mathrm{C}$ in all the specimens. The equality of enthalpies involved in the cold crystallization and the subsequent melting process led to a zero neat total enthalpy of melting, a fact that, in agreement with the X-ray diffraction results, indicates the complete amorphous character of PLA in the neat polymer and as matrix in its composites after the quench applied in manufacturing of the films. It is remarkable that the PLA under analysis showed very close temperatures for the cold crystallization and the subsequent melting process. This feature was different to the exhibited by other PLAs reported in the literature $[10,16]$ and implied some peculiarities concerning the type of polymorphs to be developed, as is commented upon below. Furthermore, the melting temperature, $T_{m}$, of this PLA under study exhibited a value unusually low compared with other PLAs reported in the literature $[10,16]$.

Figure $5 \mathrm{~b}$ concerns the cooling process at $10^{\circ} \mathrm{C} / \mathrm{min}$ (note that the y-scale has been magnified by a factor of 5 in relation to the melting curves). The only clearly observed transition was the glass transition, 
which occurred at $55{ }^{\circ} \mathrm{C}$. Its location did not change with the incorporation of the mesoporous SBA-15 particles, as already observed during the first melting. Nevertheless, the composite PLA-SBA9 (and also PLA-SBA6 in a very minor amount) additionally showed a rather small crystallization process that took place very close to the beginning of the glass transition. The slight nucleating effect observed during the first heating run for this SBA- 15 content was again noticeable. Figure $5 \mathrm{c}$ displays the results found in the second heating process, now after a cooling rate of only $10{ }^{\circ} \mathrm{C} / \mathrm{min}$, i.e., considerably slower than that applied during initial film processing. The observed glass transition was now slightly moved to higher temperatures of approximately $59^{\circ} \mathrm{C}$, as seen in Figure $5 \mathrm{~d}$. The extension of physical aging was considerably reduced compared with that observed during the first heating since samples were just cooled. Concerning the cold crystallization of PLA, it should be noted that no important variations were seen after the cooling at $10^{\circ} \mathrm{C} / \mathrm{min}$. The minimum appeared at $127^{\circ} \mathrm{C}$, and its location and intensity were not dependent on either the presence or content of mesoporous silica. After this crystallization, melting started, and its maximum appeared at $149^{\circ} \mathrm{C}$ for all the specimens. The observed effect in the ordering of this PLA by an incorporation of $9 \mathrm{wt} . \%$ in mesoporous silica for the PLA-SBA9 composite encouraged a deeper analysis of the crystallization process. Thus, isothermal experiments were performed, either from the glass or molten states.

Figure 6a shows a comparison between isothermal crystallization from the molten state for PLA and PLA-SBA9 at different temperatures.
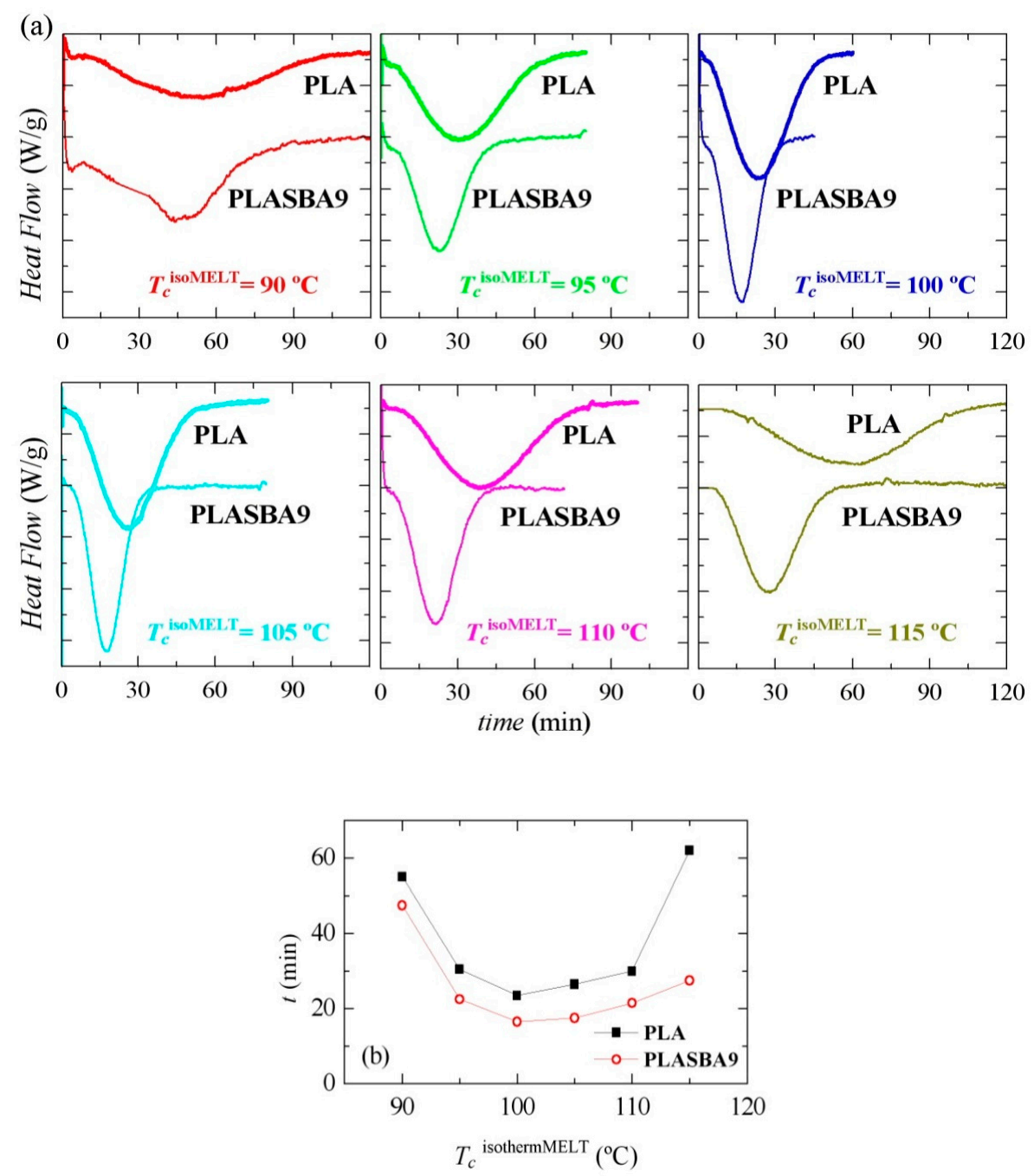

Figure 6. (a) Dependence of heat flow on time for isothermal crystallization from the melt, $T_{c}$ isothermMELT, at the indicated temperatures for PLA and PLA-SBA9. (b) Comparison of the peak crystallization times as a function $T_{C}$ isothermMELT in PLA and PLA-SBA9. 
It is noticeable that the presence of SBA-15 silica exerted an important effect and led to the acceleration of the PLA crystallization independently of the analyzed $T_{c}$ isothermMELT. Accordingly, the crystallization shifted to shorter times and was narrower in the PLA-SBA9 than in the pristine PLA at a given $T_{c}$ isothermMELT. The fastest crystallization temperature for the PLA chains from both specimens was $100^{\circ} \mathrm{C}$, as seen in Figure $6 \mathrm{~b}$. Anyway, the crystallization times involved, even at the maxima, were very long.

Figure 7 shows the successive melting processes after those isothermal crystallizations from the melt. Two different melting trends were seen with increasing $T_{c}$ isothermMELT from 90 to $115^{\circ} \mathrm{C}$. At $T_{c}$ isothermMELT $<110{ }^{\circ} \mathrm{C}$, the DSC curves showed two well-defined endothermic peaks, $T_{m 1}$ and $T_{m 2}$ at low and high temperatures, respectively. The peak height of $T_{m 2}$ relative to $T_{m 1}$ decreased and shifted to lower temperatures with increasing $T_{c}$ isothermMELT , up to $110^{\circ} \mathrm{C}$ in PLA and $115^{\circ} \mathrm{C}$ in PLA-SBA9-temperatures at which $T_{m 2}$ merged with $T_{m 1}$. Therefore, at $T_{c}$ isothermMELT $=115^{\circ} \mathrm{C}$, only a single $T_{m 1}$ melting peak was observed. The incorporation of mesoporous SBA-15 did not practically exert influence on the position of $T_{m 1}$, as seen in Figure $7 \mathrm{c}$, its effect being more significant for $T_{m 2}$. The origin of the two melting temperatures is commented upon below.
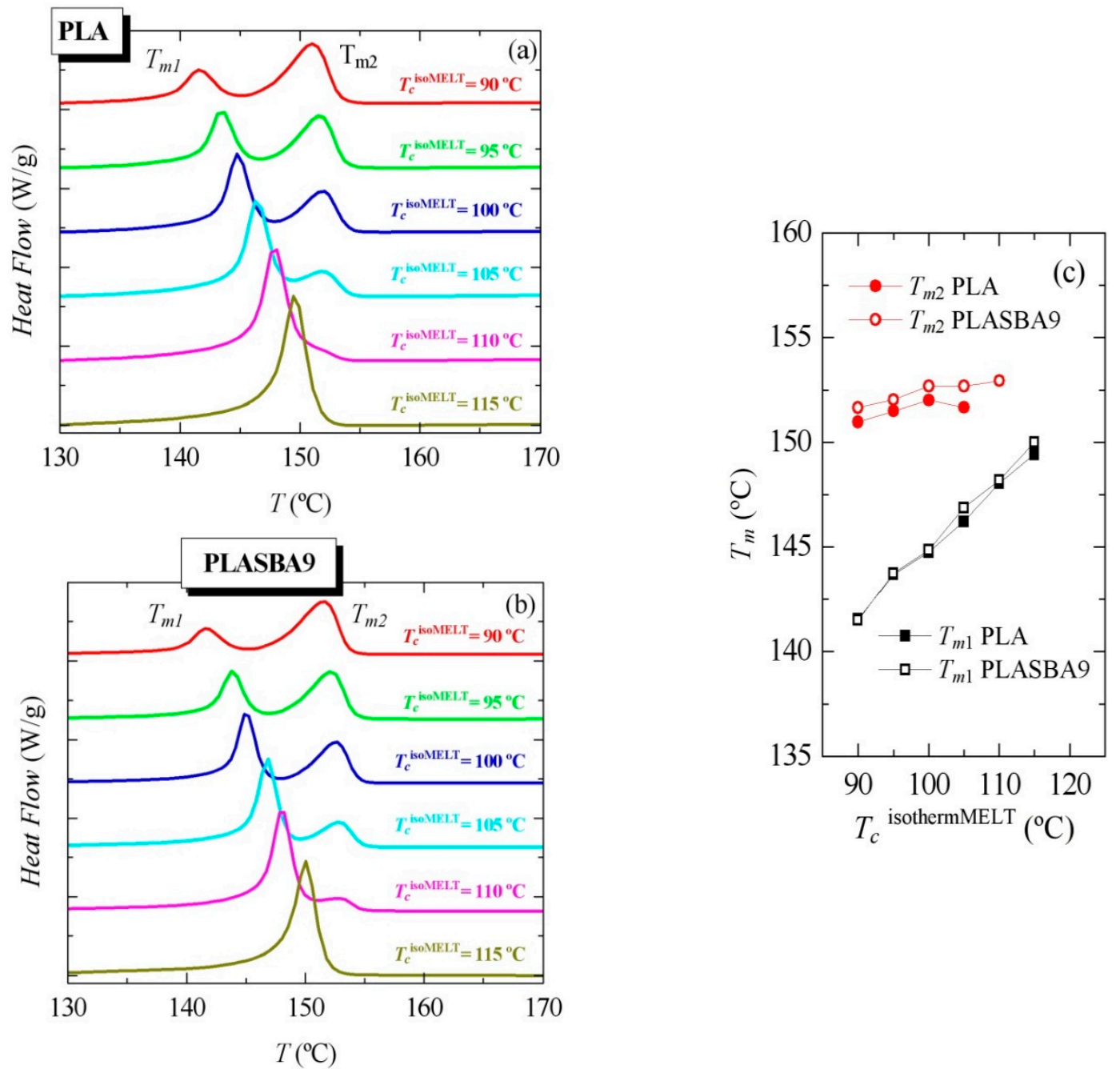

Figure 7. Effect of isothermal crystallization temperature from the melt, $T_{\mathcal{c}}$ isothermMELT, on the melting behavior for (a) neat PLA and (b) its composite PLA-SBA9. (c) Relationship of melting temperatures with $T_{c}$ isothermMELT.

Considering the rather long crystallization times for those isothermal experiments from the melt, additional isothermal crystallizations initiated from the amorphous glass were performed. Figure 8 shows the results found in a broad range of temperatures, named $T_{C}$ isothermGLASS, from 85 to $140{ }^{\circ} \mathrm{C}$. 
As noticed in Figure 8a,b, independently of the incorporation of mesoporous SBA-15, crystallization was hindered at the lowest and the highest tested temperatures, requiring long times and exhibiting low extension.
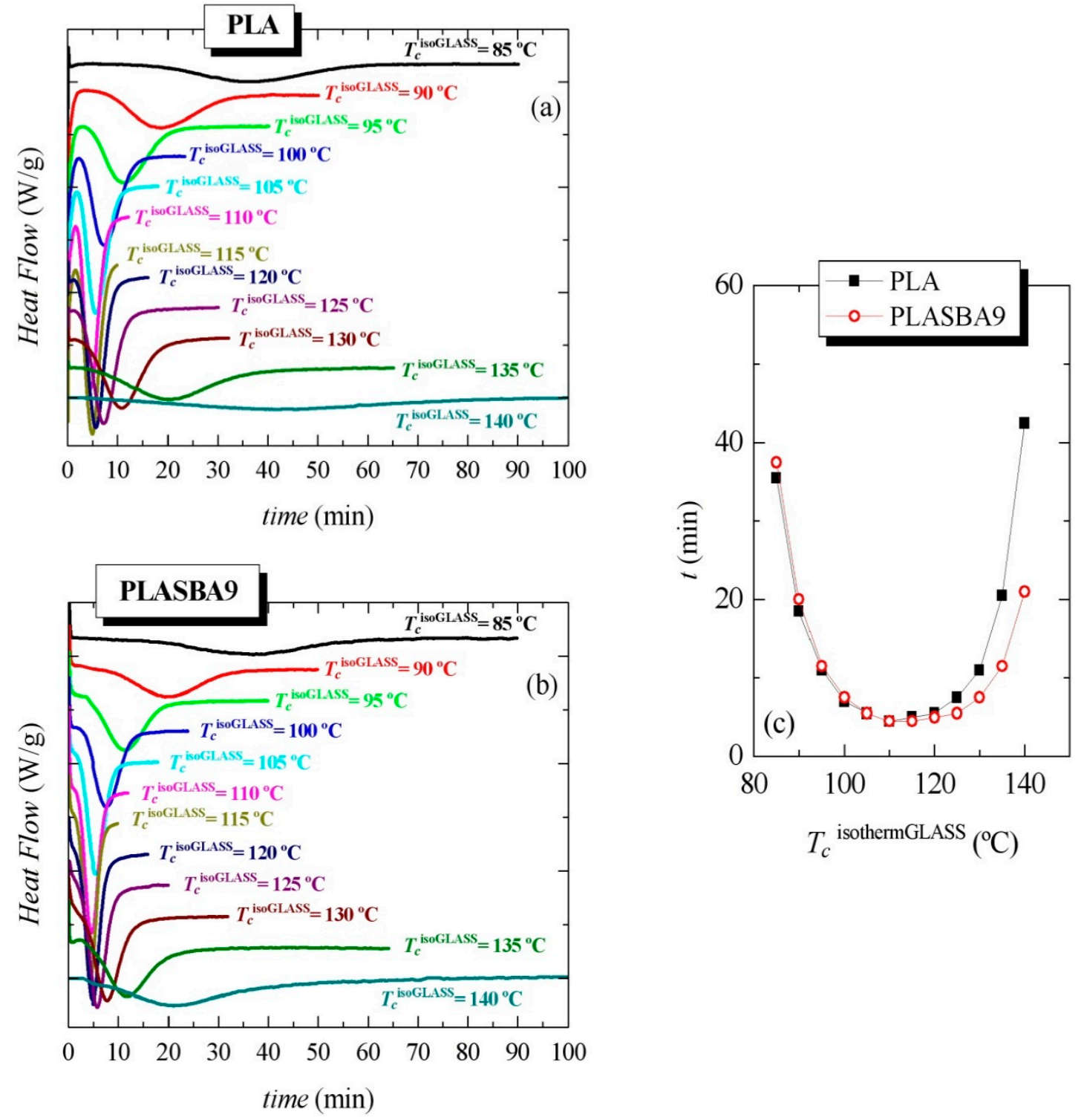

Figure 8. Dependence of heat flow on time for isothermal crystallization from the glass, $T_{c}$ isothermGLASS, at the indicated temperatures for (a) PLA and (b) PLA-SBA9. (c) Comparison of the peak crystallization times as a function of $T_{\mathcal{C}}$ isothermGLASS in PLA and PLA-SBA9.

Moreover, crystallization was moved to shorter times as temperature was increased, i.e., the ordering capability was sped up to reach a minimum (maximum rate) at around $110-115^{\circ} \mathrm{C}$, as seen in Figure $8 \mathrm{c}$. Beyond those temperatures, the crystallization started to progressively slow down. This minimum was the result of the well-known opposite effects of the nucleation and transport terms in the crystallization rate.

Nevertheless, some differences were clearly noticed by effect of SBA-15's presence. Thus, Figure 8c shows the time for peak crystallization as a function of $T_{c}$ isothermGLASS in PLA and PLA-SBA9. It was observed that isothermal crystallization from the glassy state was slightly faster in pristine PLA than in PLA-SBA9 when it took place at temperatures lower than $100^{\circ} \mathrm{C}$, although variations became smaller as the temperature rose, being practically the same at temperatures of 105 and $110^{\circ} \mathrm{C}$. Above this isothermal temperature, the effect of SBA- 15 became more important, the differences increasing as the 
isothermal crystallization temperature did, as can be seen in Figure 8c. In fact, the peak crystallization time was reduced to practically one half at $140{ }^{\circ} \mathrm{C}$ when comparing PLA and PLA-SBA9.

On the other hand, the inspection of Figures $6 \mathrm{~b}$ and $8 \mathrm{c}$ allows one to observe that PLA's isothermal crystallization from the glass, i.e., along cold crystallization, was much faster than from the molten state. For instance, the times of peak crystallization were around four-to-five times smaller in the experiments from the glassy state than from the molten state. Those high differences were also responsible of the fact that the nucleating effect of mesoporous SBA- 15 became more considerable when crystallization was initiated from the melt.

Figure 9 displays the characteristics found during the subsequent melting process after isothermal crystallization from the glass. Two different melting behaviors were again clearly noticeable with increasing $T_{c}$ isothermGLASS from 85 to $140{ }^{\circ} \mathrm{C}$. At $T_{c}$ isothermGLASS $<120^{\circ} \mathrm{C}$, the DSC curves show two well-defined endothermic peaks: $T_{m 1}$ and $T_{m 2}$ at low and high temperatures, respectively. The peak height of $T_{m 2}$ relative to $T_{m 1}$ decreased and $T_{m 2}$ shifted to lower temperatures with increasing $T_{c}$ isothermGLASS up to $120^{\circ} \mathrm{C}$, the temperature at which it merged with $T_{m 1}$. At $T_{c}$ isothermGLASS $>120{ }^{\circ} \mathrm{C}$, only a single $T_{m 1}$ melting peak appeared. The influence of presence of SBA-15 particles did not practically affect the position of $T_{m 2}$, as deduced from Figure $9 \mathrm{c}$, but the dependence of $T_{m 1}$ on $T_{c}$ was rather pronounced.
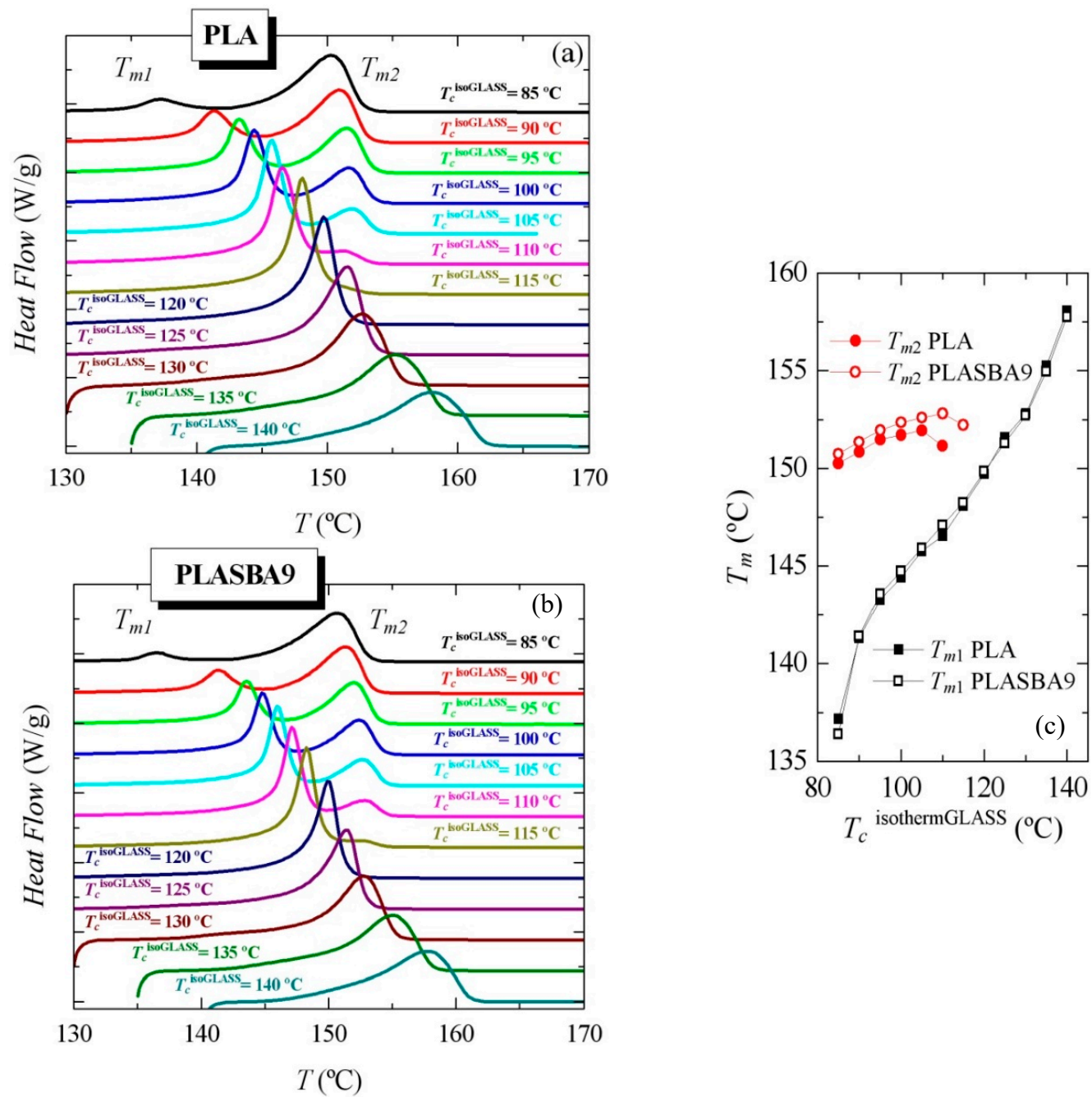

Figure 9. Effect of isothermal crystallization temperature from the glass, $T_{c}$ isothermGLASS , on the melting behavior for (a) neat PLA and (b) its composite PLA-SBA9. (c) Dependence of melting temperatures on $T_{c}$ isothermGLASS. 
Coming now to the origin of the two melting peaks, and as noted in the Introduction, two distinct crystalline polymorphs, labeled as $\alpha^{\prime}$ and $\alpha$, could be developed under most processing conditions. Different ratios of both lattices can be achieved for PLA depending on the crystallization temperature, as reported in the literature $[10,11,19]$. These reports have indicated that when the crystallization occurs below $100{ }^{\circ} \mathrm{C}$ for the studied PLA sample, almost only the $\alpha^{\prime}$ crystalline lattice is formed, and when it takes place above $120^{\circ} \mathrm{C}$, the $\alpha$ form is exclusively developed. The coexistence of both types of crystallites appears in the interval between 100 and $120^{\circ} \mathrm{C}$, their ratio being mainly varied by crystallization temperature and intrinsic PLA characteristics. Was this behavior also noticeable for the present PLA sample?

It seemed that something different took place in this PLA and its composites with SBA-15 because the usual melting of the $\alpha^{\prime}$ crystals involved its recrystallization into the $\alpha$ modification, which is characterized by an exothermic event [16]. These characteristics were not observed in the results represented in Figures 7a,b and 9a,b [19]. It seems, therefore, that the found behavior was only related to the melting of the $\alpha$ crystalline polymorph [10]. The lower-temperature peak $T_{m 1}$ refers then to the melting of the original crystals developed during isothermal crystallization, while the higher-temperature endotherm $T_{m 2}$ refers to the melting of the recrystallized entities after thickening upon melting, with very little variation with $T_{c}$. Finally, when the $T_{c}$ isothermGLASS was above $120^{\circ} \mathrm{C}$, the pristine crystals were thick enough and only a melting component was observed.

Interestingly, dependence of $T_{m 1}$ on $T_{c}$ seen in Figure 9c, shows a clear change of the slope below around $90^{\circ} \mathrm{C}$. Therefore, although the observation of the crystallization isotherm when crystallizing at temperatures below $85^{\circ} \mathrm{C}$ was not possible due to the deterioration of the signal-to-noise ratio due to the relatively high crystallization times, additional experiments were performed by annealing for long times without registering the crystallization isotherm. Thus, Figure 10 shows the DSC melting curves after crystallization for $8 \mathrm{~h}$ at the indicated temperatures from the glassy state.

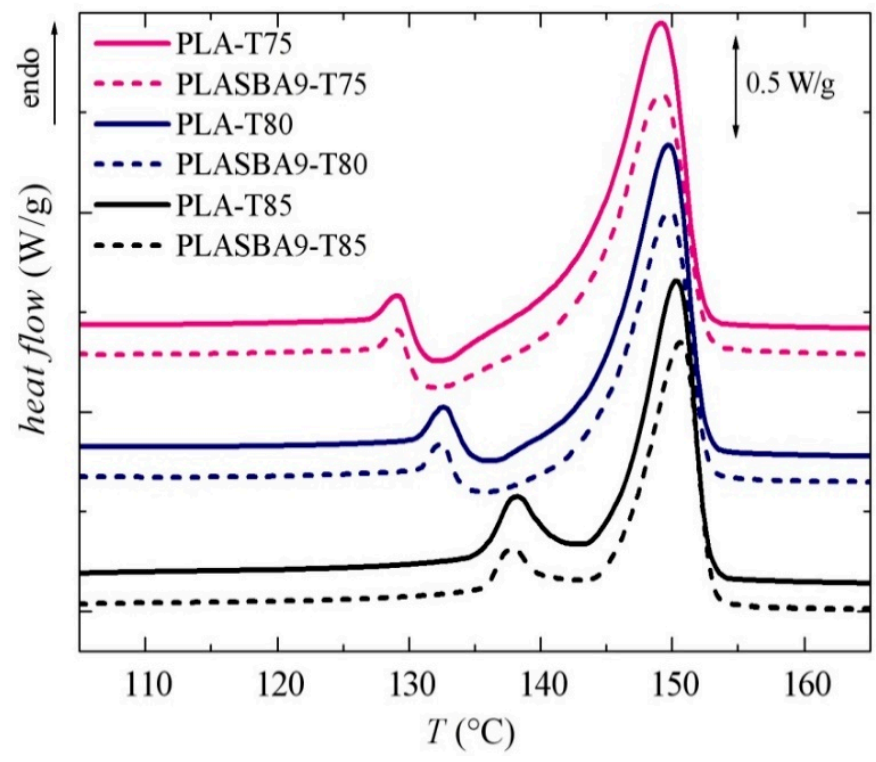

Figure 10. DSC melting curves after crystallization for $8 \mathrm{~h}$ from the glassy state at the indicated temperatures for the pristine PLA and its composite PLA-SBA9.

Now, the behavior at the crystallization temperatures of 75 and $80^{\circ} \mathrm{C}$ was that commonly observed for the melting of the $\alpha^{\prime}$ crystals with its recrystallization into the $\alpha$ modification, characterized by an exothermic event. At $85^{\circ} \mathrm{C}$, that exothermic event was not exhibited, pointing out the important hindrance of $\alpha^{\prime}$ crystal formation at that relatively low crystallization temperature. If a certain amount of $\alpha^{\prime}$ crystallites had been developed, it was small, coexisting with $\alpha$ crystals, which existed as a major amount. The melting curve of this long crystallization at $85^{\circ} \mathrm{C}$ was rather similar to that depicted in Figure $9 \mathrm{a}$, where the total crystallization time was only $90 \mathrm{~min}$. 
Considering these results and the commented change of the slope in Figure $9 \mathrm{c}$ below around $90{ }^{\circ} \mathrm{C}$, it can be tentatively said that $\alpha^{\prime}$ crystals were obtained for this PLA and its composite PLA-SBA9 when crystallizing below $80^{\circ} \mathrm{C}$, and the $\alpha$ modification was the only one obtained above $90^{\circ} \mathrm{C}$, probably with a mixture of the two forms in the approximate interval of crystallization temperatures from 80 to $90{ }^{\circ} \mathrm{C}$.

In order to ascertain that conclusion, $\mathrm{X}$-ray diffraction experiments with synchrotron radiation were performed for samples crystallized at different temperatures and times. A comprehensive study is under progress for the analysis of the melting curves subsequent to those crystallizations. For the present purpose, the results shown in Figure 11 are revealing enough, displaying the diffractograms at room temperature for samples of the neat PLA crystallized at two temperatures: 75 and $85{ }^{\circ} \mathrm{C}$. According to the literature $[11,14,54]$, these profiles are typical for a majority of $\alpha^{\prime}$ crystallites in samples crystallized at $75^{\circ} \mathrm{C}$ and of $\alpha$ crystals in samples crystallized at $85^{\circ} \mathrm{C}$. Here, they were characterized by the practical absence of reflections (103) and (010) for the $\alpha^{\prime}$ crystallites and a displacement to higher $s$ values (lower spacings) for the (110)/(200) and (203) peaks for the $\alpha$ modification.

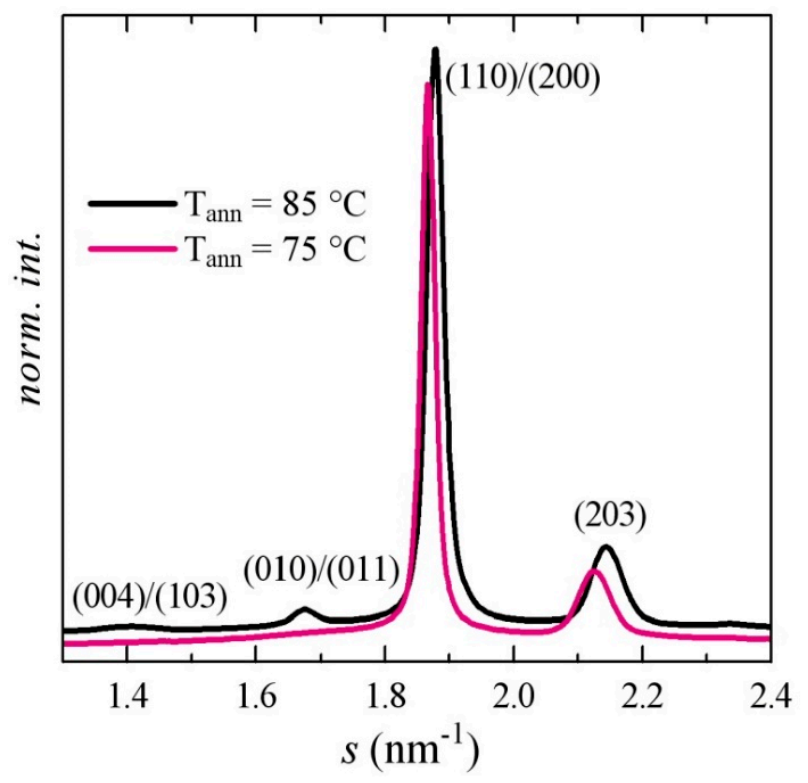

Figure 11. Synchrotron X-ray diffraction patterns at room temperature for PLA after crystallization for $8 \mathrm{~h}$ from the glassy state at the indicated temperatures. The Miller indices are indicated.

\subsection{Mechanical Response}

Microhardness measurements were performed to preliminarily estimate the mechanical response exhibited by these materials after their processing. As previously mentioned, all of them were amorphous. As seen in Figure 5d, an endothermic peak overlapped with the PLA glass transition related to its physical aging, even in those just-cooled specimens. This phenomenon, referred to as the molecular rearrangements of the amorphous PLA chains, takes place when its structure and, consequently, its thermodynamic variables (volume, enthalpy, and entropy) evolve toward the equilibrium $[55,56]$. These changes provoke variations with the aging time in the whole spectrum of properties until equilibrium is reached. Four weeks at room temperature is considered enough time [16] for the amorphous PLA phase to achieve equilibrium. This process could be accelerated if higher temperatures closer to but below $\mathrm{T}_{\mathrm{g}}[55]$ are used. Figure 12 shows the MH values for PLA and some of its composites with SBA-15 at different aging times, as well as the variation with silica content of ratio between the actual $\mathrm{MH}$ and the initial value at each sample for the several analyzed aging times. 


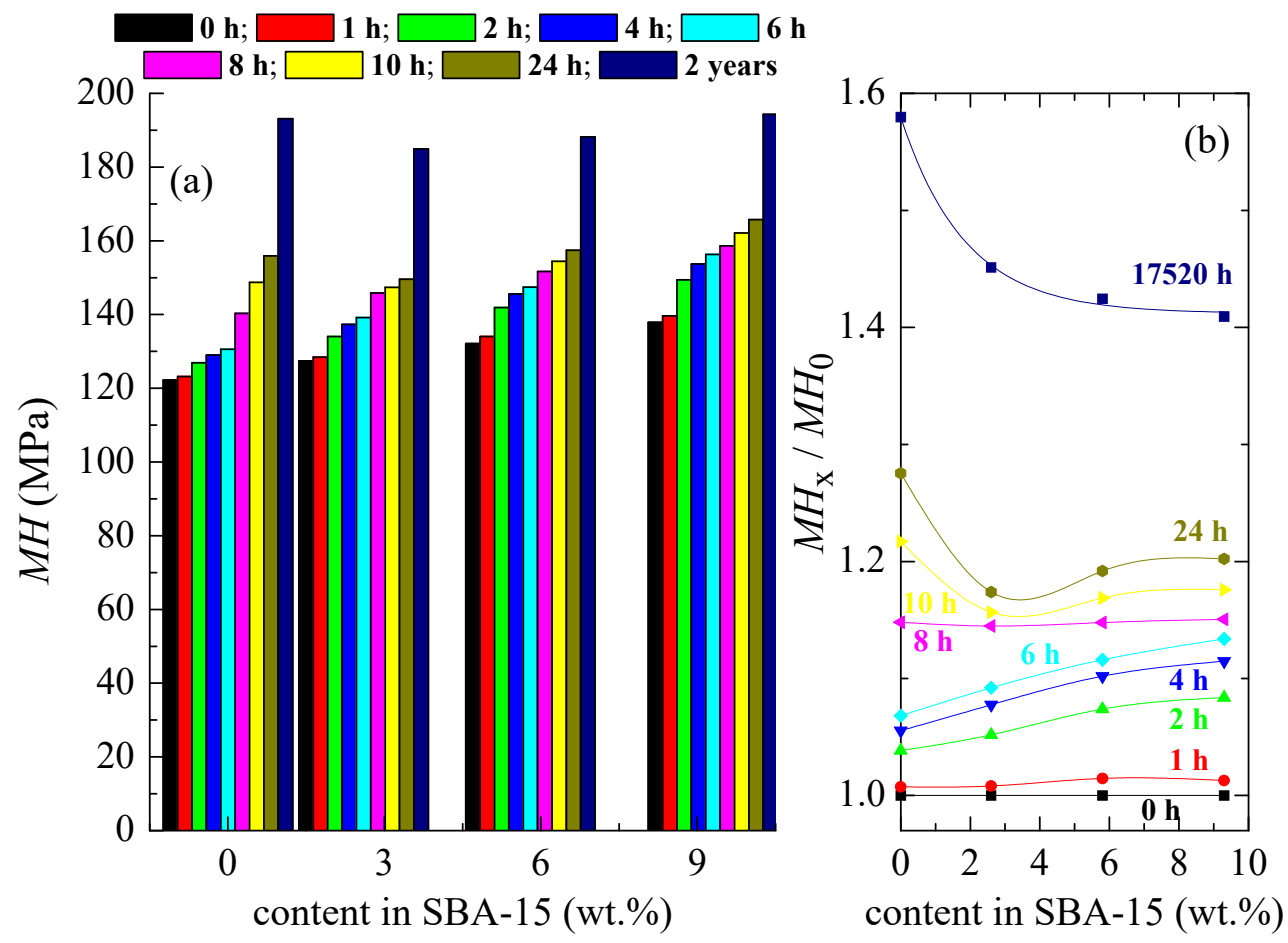

Figure 12. (a) Microhardness (MH) dependence on SBA-15 content at different aging times for neat PLA and its composites with silica processed from the melt. (b) Variation with silica content of the ratio between the actual $\mathrm{MH}$ and the initial value at each sample for the several analyzed aging times.

The just-processed specimens, as observed in Figure 12a, displayed a linear increase of MH with SBA-15 weight content, from $122 \mathrm{MPa}$ for PLA to $138 \mathrm{MPa}$ for PLA-SBA9. This fact points out the reinforcement role that mesoporous silica particles had in the amorphous glassy PLA macrochains. This tendency was expected since SBA-15 particles are harder than polymeric chains.

An analogous linear behavior (although $\mathrm{MH}$ values were raised for each sample with aging) was observed with aging time up to $8 \mathrm{~h}$ elapsed from processing. The reason why $\mathrm{MH}$ values for a specific sample were not kept constant with time was because physical aging took place in the polymeric chains (either in the pristine PLA or in the PLA matrix for the distinct composites). Tests were performed at a temperature below $\mathrm{T}_{\mathrm{g}}$, and its amorphous glassy macromolecules were out of equilibrium and evolved to reach that state. PLA volume was then diminished, as previously mentioned, and its chains became denser and, consequently, more rigid during this structural recovery to equilibrium. Then, all mechanical parameters related to stiffness increased with aging time.

Nevertheless, the linear trend was not further accomplished at aging times higher than $8 \mathrm{~h}$. In fact, values of the pristine PLA were larger than those in the PLA-SBA3 composites at $10 \mathrm{~h}, 24 \mathrm{~h}$, and 2 years. The same feature was found in the MH of the PLA-SBA6 composite for an aging time of two years. Only the PLA-SBA9 material exhibited MH values higher than neat PLA in the whole interval of analyzed aging times. What happened?

Two aspects contributed to increase rigidity: the filler effect of SBA-15 particles and the physical aging in PLA chains. The former was expected to be constant with temperature, but the latter depended on the absence or presence of SBA-15 in the materials under analysis. That means, as deduced from Figure 12b, that PLA aged faster in the neat matrix than in the composites, and this rate was inversely proportional to the SBA-15 silica content. Accordingly, the contribution of the PLA physical aging at $10 \mathrm{~h}$ from processing or longer times to rigidity in the pristine matrix was able to overcome the filler effect of an SBA-15 incorporation of $3 \mathrm{wt} . \%$. The same occurred in the PLA-SBA6 but now at longer aging times since a higher SBA- 15 content was now incorporated. Rather analogous values were observed when PLA and PLA-SBA9 were compared after two years at room temperature 
from its processing, once physical aging process was supposedly finished. Accordingly, physical aging's contribution to rigidity characteristics was really important in the pristine PLA, though it apparently secondary in the composites. However, this behavior was only valid for completely amorphous samples. MH dependence at room temperature will be different for this neat PLA and its composites if PLA crystallizes, either from the melt of from the glassy state, since other variables (crystallinity, crystallite size, type of polymorph developed, and the ratio between distinct crystalline lattices) will play a key role. Experiments are under progress for semicrystalline PLA and its materials with SBA-15 particles, all manufactured through extrusion.

\section{Conclusions}

Several composites based on an L-rich PLA with different contents of mesoporous SBA-15 were prepared by melt extrusion in order to evaluate the effect of mesoporous silica on the resultant PLA materials. These were completely amorphous since their processing as films consisted of a quenching from the melt to simulate the high cooling rates generally applied at the industrial scale. Their morphological aspects, changes in PLA phases, and their transitions, as well as some final properties, such as thermal stability and preliminary mechanical behavior, were thoroughly examined.

Morphological observations suggested a good contact at interfaces between the PLA matrix and the mesoporous silica particles. This was in agreement with the changes observed in the PLA packing, deduced from Raman experiments, associated with the establishment of some kind of interactions between PLA and SBA-15 in the composites.

The incorporation of SBA-15 particles into the PLA matrix did not exert any significant influence on the thermal decomposition of these composites under inert or oxidative atmospheres.

An important nucleation effect of the silica in the PLA was, however, found in non-isothermal experiments and also under isothermal crystallization, either from the melt or from the glassy state. Isothermal crystallization from the glass was considerably faster than from the molten state, with peak crystallization times around four-to-five times smaller in the former. These high differences were also responsible for the fact that the nucleating effect of mesoporous SBA-15 became more considerable when crystallization was initiated from the melt.

Cold PLA crystallization and its subsequent melting took places very close one another for the PLA under analysis, this feature being different to that exhibited by other PLAs reported in the literature. This behavior implied some peculiarities concerning the type of polymorphs to be developed. Thus, all the isothermal experiments that allowed for the observation of the crystallization isotherm with a sufficient signal-to-noise ratio led to the exclusive formation of the $\alpha$ modification. These isothermal experiments showed a minimum peak crystallization time (maximum rate) at around $110^{\circ} \mathrm{C}$, this minimum being the result of the well-known opposite effects of the nucleation and transport terms in the crystallization rate.

The development of the $\alpha^{\prime}$ crystals required a crystallization at temperatures below $80{ }^{\circ} \mathrm{C}$ for long times. Thus, $\alpha^{\prime}$ crystals were obtained for this PLA and its composites with SBA-15 particles when the PLA macrochains were isothermally maintained below $80^{\circ} \mathrm{C}$ for a long enough time (eight hours), while the $\alpha$ modification was the only polymorph obtained above $90^{\circ} \mathrm{C}$, probably with a mixture of the two forms in the approximate interval of crystallization temperatures from 80 to $85^{\circ} \mathrm{C}$. These remarks were ascertained based on X-ray diffraction of samples from neat PLA. Its profiles demonstrated a majority of $\alpha^{\prime}$ modification for the PLA crystallized at $75^{\circ} \mathrm{C}$ and of $\alpha$ crystals for that crystallized $85^{\circ} \mathrm{C}$.

Microhardness measurements of these amorphous PLA-SBA-15 composites interestingly indicated that rigidity behavior based on silica composition depended on two factors: the reinforcement effect of mesoporous particles on PLA and the extent of physical aging within a polymeric matrix. At short aging times after processing, the former had a prevailing role, and a linear increase with SBA-15 content was clearly noticeable. Nevertheless, the PLA physical aging of the neat matrix overcame the SBA-15's effect as a filler for the composites with the lowest silica contents at aging times longer 
than $10 \mathrm{~h}$. Accordingly, the influence of physical aging was really important in the pristine PLA and apparently played a secondary role in the composites.

Author Contributions: Conceptualization, E.P. and M.L.C.; methodology, T.M.D.-R., E.P., and M.L.C.; formal analysis, T.M.D.-R., E.B.-B., and E.P.; resources, E.P. and M.L.C.; writing—original draft preparation, M.L.C.; writing-review and editing, T.M.D.-R., E.B.-B., E.P., and M.L.C. All authors have read and agreed to the published version of the manuscript.

Funding: This research was funded by AEI/FEDER, UE (grant number MAT2016-79869-C2-1-P) and ALBA Synchrotron Light Facility. TMDR is also grateful for her pre-doctoral funding (contract number BES-2017-082284).

Acknowledgments: The synchrotron experiments were performed at beamline BL11-NCD-SWEET at ALBA Synchrotron Light Facility and authors would like to thank the collaboration and help of ALBA staff.

Conflicts of Interest: The authors declare no conflict of interest.

\section{References}

1. Auras, R.; Harte, B.; Selke, S. An overview of polylactides as packaging materials. Macromol. Biosci. 2004, 4, 835-864. [CrossRef] [PubMed]

2. Garlotta, D. A Literature Review of Poly(Lactic Acid). J. Polym. Environ. 2001, 9, 63-84. [CrossRef]

3. Puiggali, J.; Ikada, Y.; Tsuji, H.; Cartier, L.; Okihara, T.; Lotz, B. The frustrated structure of poly(L-lactide). Polymer 2000, 41, 8921-8930. [CrossRef]

4. Cartier, L.; Okihara, T.; Ikada, Y.; Tsuji, H.; Puiggali, J.; Lotz, B. Epitaxial crystallization and crystalline polymorphism of polylactides. Polymer 2000, 41, 8909-8919. [CrossRef]

5. Sawai, D.; Takahashi, K.; Imamura, T.; Nakamura, K.; Kanamoto, T.; Hyon, S.H. Preparation of oriented $\beta$-form poly(L-lactic acid) by solid-state extrusion. J. Polym. Sci. Part B Polym. Phys. 2002, 40, 95-104. [CrossRef]

6. Sawai, D.; Takahashi, K.; Sasashige, A.; Kanamoto, T.; Hyon, S.H. Preparation of Oriented $\beta$-Form Poly(l-lactic acid) by Solid-State Coextrusion: Effect of Extrusion Variables. Macromolecules 2003, 36, 3601-3605. [CrossRef]

7. Hoogsteen, W.; Postema, A.R.; Pennings, A.J.; Brinke, G.T.; Zugenmaier, P. Crystal structure, conformation and morphology of solution-spun poly(L-lactide) fibers. Macromolecules 1990, 23, 634-642. [CrossRef]

8. Stoclet, G.; Seguela, R.; Lefebvre, J.M.; Elkoun, S.; Vanmansart, C. Strain-Induced Molecular Ordering in Polylactide upon Uniaxial Stretching. Macromolecules 2010, 43, 1488-1498. [CrossRef]

9. Liu, J.; Zhang, S.; Zhang, L.; Liu, L.; Bai, Y. Uniaxial stretching of polylactide with different initial crystalline morphologies and temperature effect. Eur. Polym. J. 2014, 61, 83-92. [CrossRef]

10. Zhang, J.; Tashiro, K.; Tsuji, H.; Domb, A.J. Disorder-to-Order Phase Transition and Multiple Melting Behavior of Poly(L-lactide) Investigated by Simultaneous Measurements of WAXD and DSC. Macromolecules 2008, 41, 1352-1357. [CrossRef]

11. Kawai, T.; Rahman, N.; Matsuba, G.; Nishida, K.; Kanaya, T.; Nakano, M.; Okamoto, H.; Kawada, J.; Usuki, A.; Honma, N.; et al. Crystallization and Melting Behavior of Poly (L-lactic Acid). Macromolecules 2007, 40, 9463-9469. [CrossRef]

12. Zhang, J.; Duan, Y.; Sato, H.; Tsuji, H.; Noda, I.; Yan, S. Crystal Modifications and Thermal Behavior of Poly(L-lactic acid) Revealed by Infrared Spectroscopy. Macromolecules 2005, 38, 8012-8021. [CrossRef]

13. Cho, T.Y.; Strobl, G. Temperature dependent variations in the lamellar structure of poly(L-lactide). Polymer 2006, 47, 1036-1043. [CrossRef]

14. Pan, P.; Zhu, B.; Kai, W.; Dong, T.; Inoue, Y. Polymorphic Transition in Disordered Poly(L-lactide) Crystals Induced by Annealing at Elevated Temperatures. Macromolecules 2008, 41, 4296-4304. [CrossRef]

15. Meaurio, E.; de Arenaza, I.M.; Lizundia, E.; Sarasua, J.R. Analysis of the C=O Stretching Band of the $\alpha$-Crystal of Poly(L-lactide). Macromolecules 2009, 42, 5717-5727. [CrossRef]

16. Beltrán, F.R.; de la Orden, M.U.; Lorenzo, V.; Pérez, E.; Cerrada, M.L.; Martínez-Urreaga, J. Water-induced structural changes in poly(lactic acid) and PLLA-clay nanocomposites. Polymer 2016, 107, 211-222. [CrossRef]

17. Kalish, J.P.; Zeng, X.; Yang, X.; Ling-Hsu, S. A spectroscopic analysis of conformational distortion in the $\alpha^{\prime}$ phase of poly(lactic acid). Polymer 2011, 52, 3431-3436. [CrossRef]

18. Kalish, J.P.; Aou, K.; Yang, X.; Hsu, S.L. Spectroscopic and thermal analyses of $\alpha^{\prime}$ and $\alpha$ crystalline forms of poly(L-lactic acid). Polymer 2011, 52, 814-821. [CrossRef] 
19. Saeidlou, S.; Huneault, M.A.; Li, H.; Park, C.B. Poly(lactic acid) crystallization. Prog. Polym. Sci. 2012, 37, 1657-1677. [CrossRef]

20. Nam, J.Y.; Sinha, S.R.; Okamoto, M. Crystallization Behavior and Morphology of Biodegradable Polylactide/Layered Silicate Nanocomposites. Macromolecules 2003, 36, 7126-7131. [CrossRef]

21. Krikorian, V.; Pochan, D.J. Unusual Crystallization Behavior of Organoclay Reinforced Poly(L-lactic acid) Nanocomposites. Macromolecules 2004, 37, 6480-6491. [CrossRef]

22. Zhao, Y.; Qiu, Z.; Yang, W. Effect of multi-walled carbon nanotubes on the crystallization and hydrolytic degradation of biodegradable poly(L-lactide). Compos. Sci. Technol. 2009, 69, 627-632. [CrossRef]

23. Li, M.; Hu, D.; Wang, Y.; Shen, C. Nonisothermal crystallization kinetics of poly(lactic acid) formulations comprising talc with poly(ethylene glycol). Polym. Eng. Sci. 2010, 50, 2298-2305. [CrossRef]

24. Battegazzore, D.; Bocchini, S.; Frache, A. Crystallization kinetics of poly(lactic acid)-talc composites. Express Polym. Lett. 2011, 5, 849-858. [CrossRef]

25. Barrau, S.; Vanmansart, C.; Moreau, M.; Addad, A.; Stoclet, G.; Lefebvre, J.M.; Seguela, R. Crystallization Behavior of Carbon Nanotube-Polylactide Nanocomposites. Macromolecules 2011, 44, 6496-6502. [CrossRef]

26. Wang, H.; Qiu, Z. Crystallization behaviors of biodegradable poly(L-lactic acid)/graphene oxide nanocomposites from the amorphous state. Thermochim. Acta 2011, 526, 229-236. [CrossRef]

27. Petchwattana, N.; Naknaen, P.; Narupai, B. Combination effects of reinforcing filler and impact modifier on the crystallization and toughening performances of poly(lactic acid). Express Polym. Lett. 2020, 14, 848-859. [CrossRef]

28. Beck, J.S.; Vartuli, J.C.; Roth, W.J.; Leonowicz, M.E.; Kresge, C.T.; Schmitt, K.D.; Chu, C.T.-W.; Olson, D.H.; Sheppard, E.W.; McCullen, S.B.; et al. A new family of mesoporous molecular sieves prepared with liquid crystal templates. J. Am. Chem. Soc. 1992, 114, 10834-10843. [CrossRef]

29. Zhao, D.Y.; Feng, J.L.; Huo, Q.S.; Melosh, N.; Fredrickson, G.H.; Chmelka, B.F.; Stucky, G.D. Triblock copolymer syntheses of mesoporous silica with periodic 50 to 300 angstrom pores. Science 1998, 279, 548-552. [CrossRef]

30. Loganathan, S.; Jacob, J.; Valapa, R.B.; Thomas, S. Influence of linear and branched amine functionalization in mesoporous silica on the thermal, mechanical and barrier properties of sustainable poly(lactic acid) biocomposite films. Polymer 2018, 148, 149-157. [CrossRef]

31. Deryło-Marczewska, A.; Zienkiewicz-Strzałka, M.; Skrzypczyńska, K.; Światkowski, A.; Kuśmierek, K. Evaluation of the SBA-15 materials ability to accumulation of 4-chlorophenol on carbon paste electrode. Adsorption 2016, 22, 801-812. [CrossRef]

32. Bruckmoser, K.; Resch, K. Effect of processing conditions on crystallization behavior and mechanical properties of poly(lactic acid) staple fibers. J. Appl. Polym. Sci. 2015, 132, 42432. [CrossRef]

33. Badia, J.D.; Santonja-Blasco, L.; Martínez-Felipe, A.; Ribes-Greus, A. Hygrothermal ageing of reprocessed polylactide. Polym. Degrad. Stab. 2012, 97, 1881-1890. [CrossRef]

34. Calleja, F.J.B. Microhardness Relating to Crystalline Polymers. Adv. Polym. Sci. 1985, 66, 117-148.

35. Fonseca, C.; Pereña, J.M.; Benavente, R.; Cerrada, M.L.; Bello, A.; Pérez, E. Microhardness and thermal study of the annealing effects in vinyl alcohol-ethylene copolymers. Polymer 1995, 36, 1887-1892. [CrossRef]

36. Cerrada, M.L.; Pérez, E.; Lourenço, J.P.; Campos, J.M.; Ribeiro, M.R. Hybrid HDPE/MCM-41 Nanocomposites: Crystalline Structure and Viscoelastic Behaviour. Microporous Mesoporous Mat. 2010, 130, 215-223. [CrossRef]

37. Cerrada, M.L.; Pérez, E.; Lourenço, J.P.; Bento, A.; Ribeiro, M.R. Decorated MCM-41/polyethylene hybrids: Crystalline Details and Viscoelastic Behavior. Polymer 2013, 54, 2611-2620. [CrossRef]

38. Ferreira, A.E.; Cerrada, M.L.; Pérez, E.; Lorenzo, V.; Cramail, H.; Lourenço, J.P.; Ribeiro, M.R. UHMWPE/SBA-15 nanocomposites synthesized by in situ polymerization. Microporous Mesoporous Mat. 2016, 232, 13-25. [CrossRef]

39. Cerrada, M.L.; Bento, A.; Pérez, E.; Lorenzo, V.; Lourenço, J.P.; Ribeiro, M.R. Hybrid Materials Based on Polyethylene and MCM-41 Particles Functionalized with Silanes: Catalytic Aspects of in Situ Polymerization, Crystalline Features and Mechanical Properties. Microporous Mesoporous Mat. 2016, 232, 86-96. [CrossRef]

40. Barranco-García, R.; Ferreira, A.E.; Ribeiro, M.R.; Lorenzo, V.; García-Peñas, A.; Gómez-Elvira, J.M.; Pérez, E.; Cerrada, M.L. Hybrid materials obtained by in situ polymerization based on polypropylene and mesoporous SBA-15 silica particles: Catalytic aspects, crystalline details and mechanical behavior. Polymer 2018, 151, 218-230. [CrossRef] 
41. Barranco-García, R.; López-Majada, J.M.; Martínez, J.C.; Gómez-Elvira, J.M.; Pérez, E.; Cerrada, M.L. Confinement of iPP crystallites within mesoporous SBA-15 channels by Small Angle X-ray Scattering in extruded iPP-SBA-15 nanocomposites. Microporous Mesoporous Mat. 2018, 272, 209-216. [CrossRef]

42. Barranco-García, R.; López-Majada, J.M.; Lorenzo, V.; Gómez-Elvira, J.M.; Pérez, E.; Cerrada, M.L. Confinement of iPP chains in the interior of SBA-15 mesostructure ascertained by gas transport properties in iPP-SBA-15 nanocomposites prepared by extrusion. J. Membr. Sci. 2019, 569, 137-148. [CrossRef]

43. Barranco-García, R.; Gómez-Elvira, J.M.; Ressia, J.A.; Quinzani, L.; Vallés, E.M.; Pérez, E.; Cerrada, M.L. Variation of Ultimate Properties in Extruded iPP-Mesoporous Silica Nanocomposites by Effect of iPP Confinement within the Mesostructures. Polymers 2020, 12, 70. [CrossRef] [PubMed]

44. Qin, D.; Kean, R.T. Crystallinity Determination of Polylactide by FT-Raman Spectrometry. App. Spectrosc. 1998, 52, 488-495. [CrossRef]

45. Kister, G.; Cassanas, G.; Bergounhon, M.; Hoarau, D.; Vert, M. Structural characterization and hydrolytic degradation of solid copolymers of d,l-lactide-co- $\varepsilon$-caprolactone by Raman spectroscopy. Polymer 2000, 41, 925-932. [CrossRef]

46. Liao, C.-C.; Wang, C.-C.; Chen, C.-Y. Stretching-induced crystallinity and orientation of polylactic acid nanofibers with improved mechanical properties using an electrically charged rotating viscoelastic jet. Polymer 2011, 52, 4303-4318. [CrossRef]

47. Yang, X.; Kang, S.; Yang, Y.; Aou, K.; Hsu, S.L. Raman spectroscopic study of conformational changes in the amorphous phase of poly(lactic acid) during deformation. Polymer 2004, 45, 4241-4248. [CrossRef]

48. Yang, X.; Kang, S.; Hsu, S.L.; Stidham, H.D.; Smith, P.B.; Leugers, A. A Spectroscopic Analysis of Chain Flexibility of Poly(lactic acid). Macromolecules 2001, 34, 5037-5041. [CrossRef]

49. Kister, G.; Cassanas, G.; Vert, M. Effects of morphology, conformation and configuration on the IR and Raman spectra of various poly(lactic acid)s. Polymer 1998, 39, 267-273. [CrossRef]

50. Marcilla, A.; Gómez-Siurana, A.; Menargues, S.; Ruiz-Femenia, R.; García-Quesada, J.C. Oxidative degradation of EVA copolymers in the presence of MCM-41. J. Anal. Appl. Pyrolysis 2006, 76, 138-143. [CrossRef]

51. Aguado, J.; Serrano, D.P.; Romero, M.D.; Escola, J.M. Catalytic conversion of polyethylene into fuels over mesoporous MCM-41. Chem. Commun. 1996, 6, 725-726. [CrossRef]

52. Campos, J.M.; Lourenço, J.P.; Pérez, E.; Cerrada, M.L.; Ribeiro, M.R. Self-reinforced Hybrid Polyethylene/MCM-41 Nanocomposites: In-situ Polymerisation and Effect of MCM-41 Content on Rigidity. J. Nanosci. Nanotechnol. 2009, 9, 3966-3974. [CrossRef] [PubMed]

53. Bento, A.; Lourenço, J.P.; Fernandes, A.; Ribeiro, M.R.; Arranz-Andrés, J.; Lorenzo, V.; Cerrada, M.L. Gas permeability properties of decorated MCM 41/polyethylene hybrids prepared by in situ polymerization. J. Membr. Sci. 2012, 415, 702-711. [CrossRef]

54. Cocca, M.; Di Lorenzo, M.L.; Malinconico, M.; Frezza, V. Influence of crystal polymorphism on mechanical and barrier properties of poly(L-lactic acid). Eur. Polym. J. 2011, 47, 1073-1080. [CrossRef]

55. Struik, L.C.E. Physical Aging in Amorphous Polymers and Other Materials; Elsevier: Amsterdam, The Netherlands, 1978; Volume 82, p. 1019.

56. Celli, A.; Scandola, M. Thermal properties and physical ageing of poly(L-lactic acid). Polymer 1992, 33, 2699-2703. [CrossRef]

Publisher's Note: MDPI stays neutral with regard to jurisdictional claims in published maps and institutional affiliations.

(C) 2020 by the authors. Licensee MDPI, Basel, Switzerland. This article is an open access article distributed under the terms and conditions of the Creative Commons Attribution (CC BY) license (http://creativecommons.org/licenses/by/4.0/). 